2007

\title{
Student Perceptions of Interactive Whiteboards in a Biology Classroom
}

Christina Schut

Cedarville University

Follow this and additional works at: http://digitalcommons.cedarville.edu/education_theses

Part of the Science and Mathematics Education Commons, and the Secondary Education and Teaching Commons

\section{Recommended Citation}

Schut, Christina, "Student Perceptions of Interactive Whiteboards in a Biology Classroom" (2007). Master of Education Research

Theses. 16.

http://digitalcommons.cedarville.edu/education_theses/16 


\title{
STUDENT PERCEPTIONS OF INTERACTIVE WHITEBOARDS \\ IN A BIOLOGY CLASSROOM
}

\author{
A thesis submitted in partial fulfillment \\ of the requirements for the degree of \\ Masters of Education
}

By

CHRISTINA RENEE SCHUT

B.A. Life Science Education, Cedarville University, 2007

2007

Cedarville University 


\section{CEDARVILLE UNIVERSITY}

SCHOOL OF GRADUATE STUDIES

May 5, 2007

I HEREBY RECOMMEND THAT THE THESIS PREPARED UNDER MY SUPERVISION BY Christina Renee Schut ENTITLED Student Perceptions of Interactive Whiteboards in a Biology Classroom BE ACCEPTED IN PARTIAL FUFILLMENT OF THE REQUIREMENTS FOR THE DEGREE OF Master of Education.
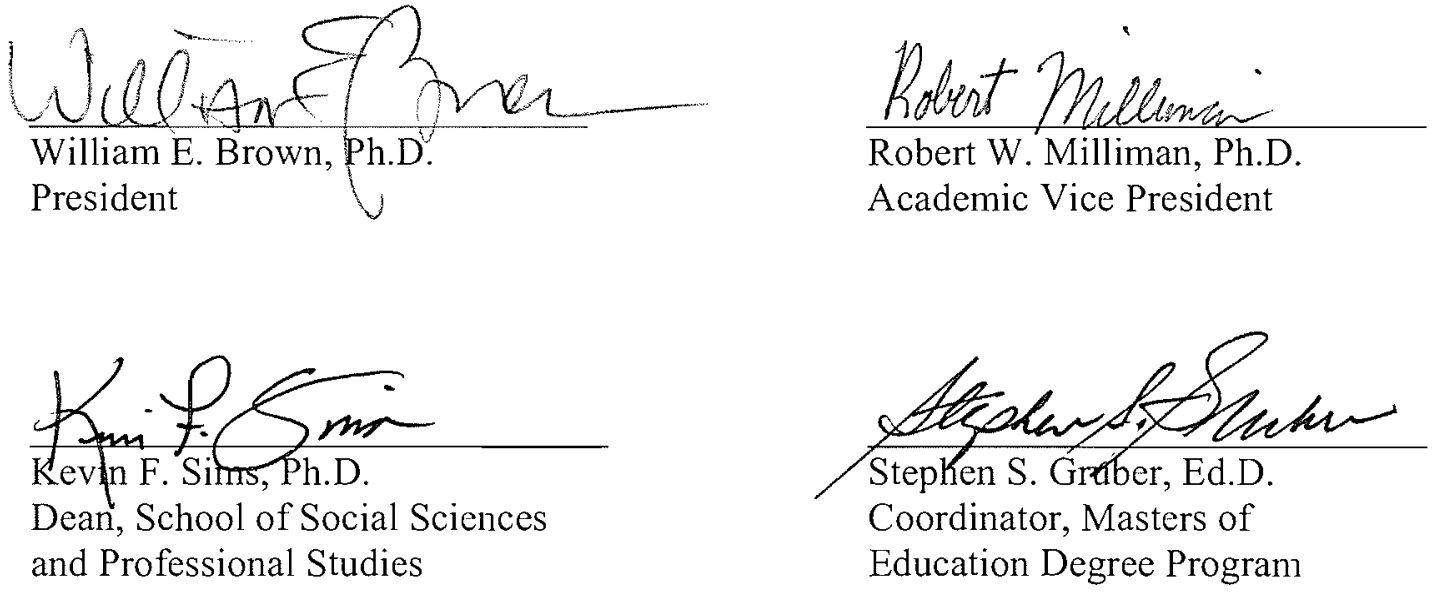

Minal w. Fin

Michael W. Firmin, Ph.D.

Psychology Department Chairman

Thesis Advisor 


\begin{abstract}
Schut, Christina R. M.Ed., Education Department, Cedarville University, 2007. Student Perceptions of Interactive Whiteboards in a Biology Classroom.
\end{abstract}

This qualitative study provides student perceptions of interactive whiteboard (IWB) use in a secondary biology classroom. The use of the IWB was alternated with the overhead on an ABAB and BABA design in two classrooms. The study was based on semi-structured interviews of thirty-six individuals, representing a sample of rural, high school students. Interview questions focused on three constructs: benefits, limitations, and suggestions for improvement. Analyzing the results ascertained that students found the IWB to be interesting because it was engaging and offered multimedia aspects. Students also reported the IWB to improve instruction through enhanced visuals and notes. Limitations and areas for improvement also were noted. These results can be used to inform educators on possible applications of the IWB's use. 


\section{TABLE OF CONTENTS}

CHAPTER I: Introduction........................................................

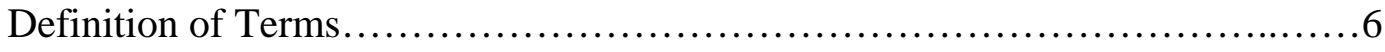

Statement of Issue......................................................... 8

Scope of the Study and Delimitations......................................10

Significance of the Study...................................................11

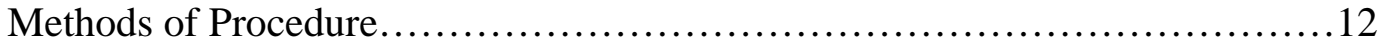

CHAPTER II: Plenary Literature Review.......................................15

History of Educational Technology ........................................15

Technology Implementation..............................................17

Benefits of Educational Technology .......................................21

Limitations and Barriers of Educational Technology...........................23

Types of Information and Communications Technology.......................24

Student Perceptions of Technology........................................26

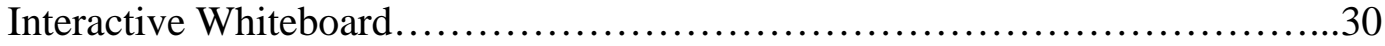

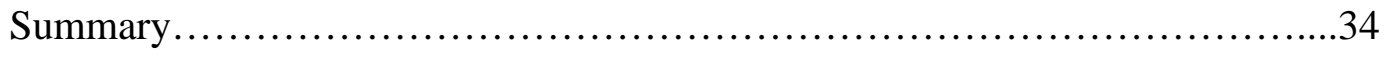

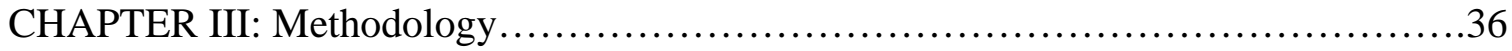

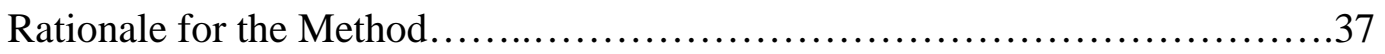

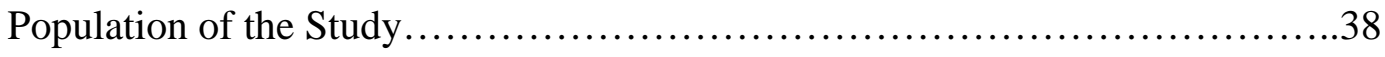

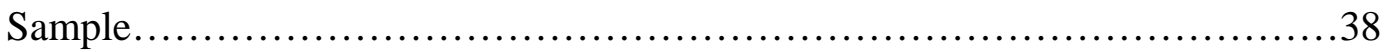

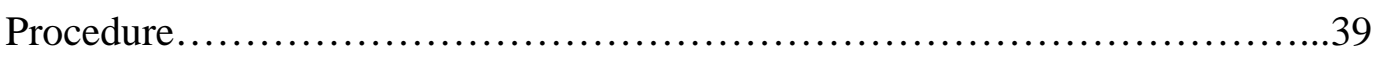

CHAPTER IV: Qualitative Findings.............................................43 
Description of the Data...............................................44

Interesting Aspects of the IWB..........................................44

Improved Instruction.............................................50

Enhancing Instruction................................................ 54

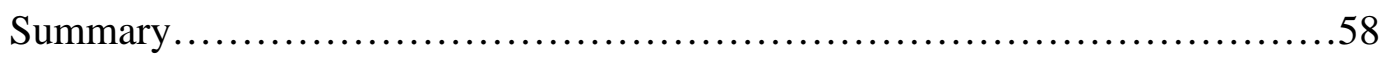

CHAPTER V: Discussion and Implications....................................59

Interpretation of the Results...........................................59

Potential Applications of the Findings...................................63

Biblical Integration...............................................66

Relation of the Results to Literature.....................................68

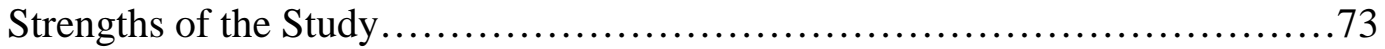

Limitations of the Study............................................74

Suggestions for Future Research.....................................76

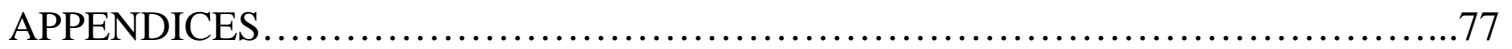

APPENDIX A: Interview Questions....................................77

APPENDIX B: Parental Consent Form..................................79

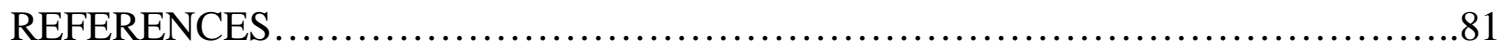




\section{ACKNOWLEDGEMENTS}

I give all praise to my Lord and Savior Jesus Christ. Your hand in my life was truly seen through this process. I pray that my life is a reflection of Your unconditional love.

I would like to thank my parents for their prayer and support through out my education at Cedarville University.

I thank my wonderful students in my biology classes at Logan Elm High School. Thank you for your patience with the details of this project. I am truly grateful for your understanding and willingness to partake in this endeavor with me. 


\section{Chapter 1}

Introduction

Technology commonly greets students as they walk into today's classrooms. This technology may include computers, software programs, LCD projectors, CD-ROMS, or interactive whiteboards. Since the 1980s public officials have formed a common goal of increasing the access of new technology in schools (Cuban, 2001). Unfortunately, the presence of technology does not imply its effectiveness (Furr, Ragsdal, \& Horton, 2005). Rather, the power of technology exists in its effective use (White, Ringstaff, \& Kelley, 2002).

One aspect of flourishing technology in schools is information and communications technology (ICT). Any type of technology involved in information and/or communication generally falls under the umbrella of ICT. This may include instructional CD-ROMs, Internet, webquests, or distance learning; these all begin with the use of a computer (Lockard \& Abrams, 2001). ICT clearly is present in classrooms, and numerous studies have evaluated ICT’s uses, benefits, and limitations.

With the prominent usage of ICT in classrooms, its value has been analyzed by multiple researchers. Williams, Coles, Wilson, Richardson, and Tuson (2000), for example, surveyed British secondary teachers to assess their use of ICT. Word processing was cited as being used most frequently, followed by external software, desktop publishing, and spreadsheets. The instructional method teachers employ with ICT use also has been researched. Often, teachers who use ICT do not change their methods; rather, they use traditional methods and adapt the ICT tools to fit (Cuban, 2001; 
Demetriadis et al., 2003). Wheeler (2001) demonstrated that since new technology brings new resources, teachers' roles must alter with this change. Teachers must reevaluate their teaching methods to integrate the technology into discussions and activities.

Most teachers recognize the benefits of ICT integration into classrooms. Williams et al. (2000), for example, found that teachers generally possess an overall positive attitude towards ICT integration. These teachers believe that it improves students' learning. Demetriadis et al. (2003) likewise found that teachers accept the need for ICT in the classroom. This ICT implementation has a positive impact on teaching as reported by Voogt, Almekinders, Van Den Akker, and Moonen (2005). They found that training resulted in teachers actively seeking to integrate technology into student learning.

Students generally report favoring the use of technology in classrooms. Pedretti, Mayer-Smith, and Woodrow (1998) analyzed student views relative to technology. They found that students viewed technology as valuable and stimulating to the learning process. Moreover, many students in the study viewed technology as an integral aspect of their education. Rodrigues (2003) studied students who used CD-ROMS and animations in learning. In both cases, students expressed both motivation and interest in learning via these mediums. Much of ICT involves the use of multimedia presentations, such as PowerPoint. Apperson, Laws, and Scepansky (2004) measured college students' experiences in a classroom that used PowerPoint. Although an increase in achievement was not established, a preference for PowerPoint and a positive class experience was. The use of PowerPoint generally was preferred over traditional lecture. Zhang and Deng (2004) demonstrated that college students perceive instructor teaching methods more positively in multimedia classrooms over traditional classrooms. In short, technology is 
beneficial, in part, due to its capacity to create an enlivening, challenging, and rewarding environment (Venezky, 2004).

A technology-rich environment also possesses limitations. A case study by Lovelass (2003) revealed many teachers expressing concern about the demands to keep pace with emerging technologies. However, these attitudes changed positively with increased access and training. ICT alone does not improve learning, but its integration and employment into the curriculum will achieve learning gains (Sutherland et al., 2004). This integration requires effort and time; therefore, teachers must possess a positive attitude towards ICT in the classroom so that teacher frustration does not negatively impose upon its implementation (Albirini, 2006; Demetriadis et al., 2003).

Although the prominence of ICT in the classroom seems promising, teacher training must be supported and adequately implemented to ensure its success. Technological support is the main concern reported among teachers (Brown, 2006; Demetriadis et al., 2003). This conclusion is exemplified in a study by Wood, Mueller, Willoughby, Specht, and DeYoung (2005). They interviewed secondary teachers on perceived barriers to using technology in their classrooms. The primary theme found was support issues which included materials, human resources, training, and administrative backing. Teaching issues such as pedagogy, skills, and curriculum were the second common theme. Also, many teachers confessed to being uncomfortable with some technology. Similarly, Brown (2006) revealed that the measured attitudes of teachers toward technology increased with training, and those who limited technology use tended to be those who lacked expertise. Voogt et al. (2005) also demonstrated the need for teachers to experience hands-on technological training to ensure successful 
implementation in the classroom. Clearly, training is required for teachers to be confident in the use of ICT.

Forms of ICT in the classroom have revolutionized since the first computer. One emerging aspect of ICT is the interactive whiteboard (IWB). This medium is becoming the new chalkboard in classrooms (Butler, 2005). The main distributor of the IWBs is SMART Technologies, and its first IWB was introduced in 1991 (SMART Technologies, 2006). These boards can be a permanent fixture in the classroom, or they can be portable. The entire portable set-up includes a touch-sensitive board, computer, LCD projector, and software (such as SMART). The LCD projector casts the computer image onto the board. The board is oriented by physically touching the Xs on the screen. The board then acts as a touch-screen computer monitor, so one's finger can be used as a mouse on the board. To write on the board, the instructor may use four colored, electronic pens and an eraser. The IWB serves multiple capabilities, and its purpose is to permit access of digital resources for the whole class (Hall \& Higgins, 2005). Some of these uses include writing notes on the board, displaying diagrams, browsing the Internet, presenting video clips, and projecting PowerPoint. Also, teachers can use the pens to write over anything on the screen to emphasize importance. Everything generated can be saved for later retrieval. These variety of uses illustrate the attractiveness for an increased presence of IWBs in the classroom.

Since IWBs are relatively new and the use of IWBs is still rising in classrooms, a present paucity of research literature exists regarding its effectiveness. Hall and Higgins (2005) and Wall, Higgins, and Smith (2005) published two seminal studies completed in British primary classrooms. Hall and Higgins (2005) indicated that IWBs were viewed 
favorably by both students and teachers. They also noted its versatility and multimedia capabilities. The IWB's versatility stems from its ability to present a range of resources from a Word document to video clips. Also, its multimedia capabilities tend to draw students of all learning types. Students found the multi-sensory environment of color, sound, and movement engaging, and they believed that it aided their learning. Proper use of the board increases interactivity in the classroom, which results in engagement and enjoyment.

Research by Wall et al. (2005) also focused on the IWB's effect on teaching and learning with year six students (between ages 10 and 11). Both positive and negative comments were noted. Students viewed IWBs positively because they alleged that it facilitated and initiated learning. A common remark by students in providing feedback was that they enjoyed the chance to use the board themselves. The students also commented that the IWBs aided the teacher in explaining concepts. Negative aspects of the IWBs included technical difficulties and limited student access. Some students also complained that they could not always view the board due to its size or the sun's glare. Another negative view held by teachers was the lack of training. Hall and Higgins (2005) and Wood et al. (2005) both noted the salient need for teacher training on this new piece of technology. This element is crucial to ensure effectual integration into the classroom. Venezky (2004) also affirmed that professional development is essential for integration of technology and learning. 


\section{Definition of Terms}

Educational technology- A specific subject or concept can be taught by integrating technology to meet the educational goal. Any form of technology, such as computers, calculators, interactive videodiscs, or CD-ROMS, can be considered educational technology when used to reach an instructional goal (Stallard \& Cockard, 2001).

CD-ROMS- This is a compact disc-read-only memory instruction tool. Often, it is a type of multimedia presentation or interactive software that the teacher presents or students interact with individually (Roblyer, 2006).

Computer-Assisted Instruction (CAI)- This software is designed to help teach facts or skills in a certain subject area (Shelly, Cashman, Gunter, \& Gunter, 2004).

Distance Learning- When learners are physically separated from each other, distance learning can occur. It is accomplished through audio and video conferencing to aid instruction and communication (Lockard \& Abrams, 2001).

Hardware- This involves the physical mechanisms of a computer. It includes the central processing unit, memory, input devices such as a keyboard, output devices such as display screens, printers, and storage devices (Lockard \& Abrams, 2001). Information and Communications Technology (ICT)- Any type of technology that will store, retrieve, manipulate, transmit, or receive information can be considered ICT. This includes a plethora of tools such as computers, e-mail, software, and Internet (Introduction-What is ICT, 2006).

Instructional Technology- An aspect of technology that directly addresses teaching and learning can be considered instructional technology. This includes any piece of technology that is incorporated into a teacher's method. 
Interactive Videodisc (IVD)- This involves a video monitor and videodisc player. The user can respond to choices presented on the screen. It has the capacity to serve many functions such as simulating lab experiments, holding visual databases, presenting tutorials, and demonstrating technical procedures (Lehman \& Brickner, 1996). Interactive Whiteboard (IWB)- This board connects to a computer in which it becomes an interactive screen with the touch of a finger. The board possesses multimedia capabilities such as displaying text, graphics, and video clips for the whole class to view (SMART Technologies, 2006).

Internet- This is a worldwide collection of networks that links together businesses, governments, educational institutions, and individuals. The main activities used include the World Wide Web (WWW) and communication functions such as e-mail (Shelly et al., 2004).

Laptop- This is a small stand-alone personal computer. It is often lightweight and portable (Roblyer, 2006).

Learning Types- Students learn in specific manners, and they generally fall among three types of learning. These include audio, visual, and kinesthetic learners.

Liquid Crystal Display (LCD) Projector- A LCD projector enables a computer image to be projected onto a large screen for group viewing (Lockard \& Abrams, 2001).

Multimedia- This term refers to multiple medias and includes any computer system that incorporates many aspects such as sound, graphics, text, and/or video (Roblyer, 2006). PowerPoint- This is a type of presentation software commonly used in classrooms. PowerPoint is a Microsoft program that allows one to program electronic presentations 
with text, graphics, and movement of slides. Then it can be presented on a large screen through a LCD projector (Roblyer, 2006).

SMART Technologies- This is a main distributor of interactive whiteboards. It was founded in 1987 and introduced the first interactive whiteboard in 1991. It joined with Intel Corporation in 1992 to increase its exposure through joint product and marketing development (SMART Technologies, 2006).

Software- These are programs written in computer language that enable the computer to perform desired tasks. These programs can be written by a user or purchased (Lockard \& Abrams, 2001).

Webquest- In a webquest students explore given websites to complete an assignment. This may include discovering new information or analyzing a topic (Roblyer, 2006). Word Processing- The computer can be used for typing and editing documents. It allows for control over page layout and incorporates writing aids such as spell check and a thesaurus (Lockard \& Abrams, 2001).

\section{Statement of Issue}

New technology produces excitement as well as questions and concerns. Since a substantial amount of time, money, and effort is invested in technology, it must exhibit learning value for students in order to justify its expense. ICT has been extensively researched. However, since the interactive whiteboard is a fairly new entity, it has not yet been widely studied. As stated earlier, research has been conducted at the primary levels, (Hall \& Higgins, 2005; Wall et al., 2005) but appraisal at the secondary level is lacking. Since IWBs are increasingly present in the classroom, knowing the perception of students at the secondary level is needed. Assessing a specific subject area is needed since 
experiences across multiple subjects may produce inconsistent results. Students' experiences may differ substantially among various subject fields.

The particular teaching domain where I focused was biology. Over the years, multiple teaching methods involving technology have emerged in biology. The entrance of the computer in schools resulted in computer-assisted instruction (CAI). This operated often in a drill-and-practice manner in order to teach facts and/or skills (Shelly et al., 2004). The advancement of this technology resulted in multimedia capabilities. One of the first multimedia instructional technology tools was interactive videodiscs. These involve a video monitor connected to a videodisc player. The user is able to select choices to navigate through the videodisc. Interactive videodiscs can be used for many purposes including simulating lab experiments, serving as electronic books, or maintaining visual databases (Lehman \& Brickner, 1996).

The rise of the Internet in the 1990s brought several new practices. One popular instructional method that emerged in the classroom was webquests. These are teacherdesigned activities in which the students use the Internet to discover information or solve problems (Simpson, 2005). Other technology enhancements include virtual tutorials, fieldtrips, or interactive multimedia tutorials. These allow students to achieve an academic experience with limited expense. These virtual experiences often can be found on the Internet or from CD-ROMs. The quality of graphics has dramatically improved since educational technology originally began, and this has produced clarity to many complex concepts (Gabric, Hovance, Comstock, \& Harnisch, 2005). Observably, technology has impacted educational tools used in the science classroom. The use of the IWB has the potential to continue transforming the face of teaching biology. In order to 
assess this possibility, students' perceptions of the benefits and limitations of the IWB in a biology classroom were researched.

Scope of the Study and Delimitations

In this study, I collected data on students’ perceptions of the benefits and limitations of the IWB's use in the biology classroom. I also assessed areas where students communicated needs for improvement in its use. The study was performed in a rural, public high school with an enrollment of about 700 students. The student population consisted of 98\% Caucasian, 13\% economically disadvantaged, and 15\% diagnosed as learning disabled. The project focused on students in two biology II classes. Biology II is an upper-level class that consists of high school sophomores, juniors, and seniors. The minimum prerequisite for the class is a C in college-prep biology. Regarding the IWB, all the teachers, including myself, received one training session on June 5, 2006. Also, the librarian was versed in the IWB's use and assisted teachers as needed. Due to the scope of this study, the reported results are reasonably generalizable to other populations of public high school biology students with demographics similar to the study’s sample.

This project focused only on biology students’ perceptions of the IWB. Teacher perceptions were not considered as part of the present study. Also, other subject areas were not included in the study. However, many of my students did experience the IWB's use in other classes. As a result, this phenomenon of interactive effects may have influenced their perceptions of the IWB's use in my class. Since the purpose of this study was to delineate students’ perceptions, specific academic gains were not tracked. 


\section{Significance of the Study}

With the rising use of emergent technology such as IWBs in the classroom, it is imperative to measure its value. A typical IWB involves a substantial investment of money, relative to a school district's budget. For example, the board can range from \$1000-\$2000. This includes the board, software, upgrades, and access to online-training. A projector also is needed, and these can cost about $\$ 1000$ (Loschert, 2004). Finally, a computer is required, and many schools choose to purchase laptops for ease of teachers' use. These purchases can total $\$ 3000-\$ 4000$ for one IWB set-up. Consequently, educators need to know the educational worth of IWB technology to the students. It is crucial to research students' perceptions of the IWB's benefits and limitations at the secondary level, and my study will contribute to this end.

The perceived benefits of the IWB by students must be investigated. If students do not recognize value in its use, then the technology’s employment may be questioned or students and teachers may need to be better prepped on its use. On the other hand, if students view it as a valuable element of instruction, then its use should be further encouraged. Some research has been conducted regarding the students' perceptions of technology in general, but this often has been conducted at the college level (Apperson et al., 2004; Zhang \& Deng, 2004). Specific research on high school students’ perceptions of the IWB is lacking. Thorough research studies with the IWB have been conducted at the primary level (Hall \& Higgins, 2005; Wall et al., 2005). However, the view of secondary students may differ from primary level students and college students. Therefore, it is essential to explore secondary level students' perceptions of the IWB's benefits. 
Any piece of technology brings limitations with its use. It is necessary to analyze these. Doing so will allow appropriate measures to be taken by educators to eliminate or reduce these barriers. The benefits drawn by the technology must be weighed against the shortcomings. Potential limitations revealed by the action research in my present classes also may be useful to other high school biology teachers.

In addition to assessing perceived benefits and limitations of the IWB, areas for potential improvement also were determined from the students. It is clear from published research that technology is not always used effectively (Lawrenz, Gravely, \& Ooms, 2006). Often students can perceive this and provide constructive feedback. Therefore, student input regarding technology utilization is important because students may share potential blind spots useful for learning improvement.

Methods of Procedure

Research questions:

1. How do biology students perceive the benefits and limitations of the IWB when compared to traditional instruction?

2. In what areas do students see needs for improvement of the IWB's use in the biology class?

This action research focused on my students’ perceptions when I used the IWB.

The research was conducted in a qualitative manner with a quasi-experimental design. It was an inductive approach in which I collected data, and then I formed hypotheses from this acquired information. The data was collected in the form of written journals and interviews. In analyzing the data, I sought to assess themes regarding the perceived benefits and limitations of the IWB. I also looked for areas where students communicated 
needed improvement. As a field study, the research was conducted in the natural environment of the biology II classroom.

My sample consisted of two biology II classes which contained Caucasian sophomores, juniors, and seniors. These students were assigned to my classes; class A contained 14 students, and class B contained 22 students. I collected journal and interview data from every student.

This study lasted eight weeks and was conducted using an ABAB design. I alternated my use of the IWB between the two classes equally. The following pattern was established:

Class A: 2 weeks IWB/ 2 weeks no IWB/ 2 weeks IWB / 2 weeks no IWB

Class B: 2 weeks no IWB / 2 weeks IWB/ 2 weeks no IWB/ 2 weeks IWB

The classes each met daily for 90 minutes. Each class contained the same content, methods, and assessments. The only differing variable was the use of the IWB. The main use of the IWB during lessons included PowerPoint, 3-D visuals, animations, note taking, and manipulation of objects. For the class in which I did not (at the time) use the IWB, transparencies, handouts, and board drawings supplemented my lectures for visuals. The overhead projector was the main method of presentation for those particular periods. This was the traditional method that I used previously in teaching, which has been positively evaluated by my principal and cooperating teachers. The research focus was students’ perceived levels of enhancement that the IWB created in biology II class. 
During the eight weeks of data collection, the students maintained running journals of their class experiences. Students wrote in these journals three times per week. They were color-coded by class and kept in the classroom. In each journal entry, they wrote about their experiences in class that particular day. This included class activities, helpful learning strategies, and suggestions for improvement. All the journal entries were organized by date. This allowed me more easily to compare reactions of IWB use and traditional teaching for each entry. At the end of the eight weeks, I conducted 10-15 minute semi-structured interviews with all students. The interviews focused on three constructs: benefits, limitations, and suggestions for improvement. A second round of interviews was conducted on a select group of students. All interviews were tape recorded and transcribed for later analysis.

In analyzing the data, I underwent the process of coding in which I looked for common themes among the three constructs. I performed the first round of coding the transcripts through constant comparison of reoccurring constructs in the data. Subsequently, I added any emerging codes and removed codes that were not consistently reported. This provided me with a master list of codes. Then I assessed the data for findings that repeated themselves among the participants interviewed in the study. Themes only were included where most of the participants consistently supported the conclusions. 


\section{Chapter 2}

\section{Plenary Literature Review}

Technology infiltrates society. Interactive White Boards (IWBs) exist in the broader context of a rich technological history. Over the past 60 years of technology's existence, it has transformed students' daily lives. The presence of technology began in the business place and slowly infused the educational setting. A historical perspective helps place IWB technology into a meaningful context.

\section{History of Educational Technology}

The dawn of the computer age occurred during the 1940s-1960s. During this time, computers were used primarily by large corporations or government offices. Once their use was established there, smaller businesses began employing technology in the form of personal computers during the 1970s (Stallard \& Cockard, 2001). In the 1980s, computers began appearing in schools. Educators’ aims were to teach basic computer skills to students (Henderson, 1999).

During the excitement of educational technology in the mid-1980s, Apple computers began an experiment known as Apple Classrooms of Tomorrow (Apple, 1995). The longitudinal study began in seven classrooms across the United States. In these classrooms, the goal was to create an educational environment that routinely used technology. This was accomplished by placing computers at home and at school for each teacher and student to ensure continual access. The purpose was to observe the effects of technology on teaching and learning. This project extended through the next decade as Apple Corporation expanded its research and amplified its voice in the educational arena. 
Multiple reports were published in which Apple communicated the positive effects of technology on both teachers and students. These findings became an initial catalyst for integrating technology in schools across the nation.

The Internet then proliferated in the 1990s, and technology changed shape as computers became networked around the world (Stallard \& Cockard, 2001). It was also during this time that the need to train teachers became pronounced and administrators began budgeting monies for teacher training. A government report in 1995 titled, Teachers and Technology: Making the Connection, noticed the lack of pre-service teacher training in technology and encouraged colleges to include technological training in education programs. As teacher training increased, technology expansion continued in schools. According to the National Center for Education Statistics (NCES, 2005), the percent of public schools with Internet access increased from 35\% to 99\% from 19942002. Today, some teachers consider aspects of technology central to their daily instruction. The NCES (2005) reported that $68 \%$ of teachers believe that e-mail is imperative, and $61 \%$ believe that Internet connection in classrooms is essential for instruction and planning. This finding also was seen in a national survey of technology literate teachers. Using e-mail to communicate with colleagues was reported as the most frequent use of technology (Teachers and Technology, 1995). Clearly, since its initial introduction, the use and existence of technology has increased in the classroom. As reported by the CEO Forum on Education and Technology (2001), 47\% of teachers used computers for daily planning and teaching in 1998, and this increased to $76 \%$ in 2000 . The student to computer ratio also has increased. In 1996 it was 10:1, and by 2000 it was $5: 1$ 
Numerous government proposals have been the catalyst for technological change in schools. Both state and local curriculum frameworks now include technological standards. In fact, Vail (2003) argues that it would be nearly impossible for schools to meet federal requirements without using technology. The No Child Left Behind Act (2001) sets forth numerous initiatives relating to technology. One of its goals is to encourage teachers to integrate technology into instruction with the goal of improving student achievement. Another goal is to include high quality professional development programs in the form of technological training for teachers.

Recommendations for education also are set forth by the National Education Plan (2004). The plan first involves strengthening leadership. This includes making an investment in developing tech-savvy leaders at all levels of education. Another recommendation involves improving teacher training to facilitate effective use. Encouraging schools to move towards a digital content in the form of multimedia or online information is recommended also. The plan asserts that today's society qualitatively functions differently with technology. Therefore, it follows that schools should operate differently as well. This may include a move away from traditional, paper textbooks and a move towards multimedia presentations and/or electronic textbooks. Potentially beneficial results would include decreased costs, increased efficiency, improved access, and enhanced learning capabilities.

\section{Technology Implementation}

Introducing technology in schools can occur only with substantial financial investment. Culp, Honey, and Mandinach (2003) provide three arguments for technology investments. First, technology is a tool to address challenges in teaching and learning. 
These uses include analyzing student data, broadening access to information resources, and encouraging creative means of writing and presenting material. Second, technology promotes change. It has the capacity to revise teaching styles, enrich content, and engage students. Third, technology is a central force in economic competitiveness. Technology literacy is crucial as students leave the educational system and enter the workforce. As technology integration continues in schools, change in how students are educated is necessitated. Culp et al. (2003) proposes many recommendations. Similar to other initiatives, he advises for technological support and teacher training. In addition, he details the need for further research in this domain. If technology is being used in the classroom, then educators must understand its impact on teaching and learning.

Technology integration in schools does not occur overnight; it is a process. The CEO Forum of Education and Technology (2000) advocates four phases of technology integration for schools, which are similar to a business' plan. First, schools assess, investigate, and experiment with technology. Second, schools make an initial capital investment. Third, schools readjust to the technology in order to maximize its use and efficiency. This likely is the phase where most schools currently reside. The final phase is the emergence of network and organization models requiring a new sense of flexibility. The numerous types of technology being integrated in the classroom reside under the general category of Information and Communications Technology (ICT). This involves technology such as computers, e-mail, Internet, CD-ROMS, multimedia presentations, and distance learning.

Wiske (2000) established three needed conditions for educators who desire technology integration. First, technology must possess significant educational value. 
Second, technology must be affordable. Finally, methodological shifts need to occur. This means that technology alone will not alter teaching practices; rather, teachers must change with the technology. For technology integration to occur, Wellington (1999a) identified several key aspects needed to promote ICT use in schools. These include access, technical support, and a positive attitude by the staff.

Many teachers are traditionalists. They often are resistant to modifying their methods. Consequently, persuading teachers to embrace new technology can pose a particular challenge (Vail, 2003). Illustrating this phenomenon, Zhao and Cziko (2001) studied teachers' implementation of ICT. They discovered that for teachers to incorporate ICT in the classrooms, they must believe that a piece of technology will be effective at reaching a specified instructional goal and that it will not cause disturbance in the process. Once schools have invested in technology, Zhao and Cziko found that teachers must grasp onto the technological transformations in order for technology to succeed. Appropriate incorporation of ICT has the capacity to enhance teaching and learning (Sutherland et al., 2004). Technology by itself does not improve learning, but it can empower new methods of teaching and learning (Kirkwood \& Price, 2005). For this to be accomplished, Furr et al. (2005) argues that technology must be viewed as a means to reach a goal. It is just one of the various tools used in classrooms to enhance instruction. As teachers use ICT they should be realigning and further developing their teaching methods (Sutherland et al., 2004). According to Wheeler (2001), a teacher's role changes with technology use. As such, teachers cannot maintain status quo with the emerging technologies. A significant reason is that the resources change. Tools common in today's classroom, such as blackboards, may soon become obsolete. Wheeler further 
argues that teachers need to be creative and explore the many uses of ICT because it can transform the knowledge of a teacher's subject area. For maximum technology effectiveness, Sutherland et al. (2004) also believes that a balance must exist between whole class and individual technology use since it is the individual interaction with technology that energizes students.

Successful technology implementation relies on professional development (Venezky, 2004). Iding, Crosby, and Speitel (2002) obtained suggestions from teachers on the school's role in supporting teacher interest in computer use. The most frequent response was for schools to provide workshops and in-service training. However, in the many schools Venezky researched across the world, he found that professional development often is not budgeted in the schools. The schools that did implement training found it to be successful in promoting technology use by teachers. For example, in one school teachers could schedule assistance from other teachers. At another setting, a core group of teachers were trained, who then assisted other teachers with technology. Many other schools developed on-the-job staff development. All these programs allowed technology use to flourish as teachers were taught technology skills and methods for integrating technology in pedagogy. These findings were echoed by Pelgrum (2001) as he reported that new technology requires proper training to succeed. Research also has shown that the training needs change as teachers become more proficient with technology. Both technical and instructional support is required as teachers expand technology use in the classroom (White et al., 2002). 


\section{Benefits of Educational Technology}

ICT use in the classroom affords many benefits as it creates a rich learning environment (Heide \& Henderson, 2001). As a result of more than a decade of research, The Apple Classrooms of Tomorrow reported multiple benefits of educational technology in the classroom (Apple, 1995). At the end of their first year of research, in the late 1980s, they reported the following outcome measures: students were performing well (or better) on tests, students wrote more effectively, and students finished units of study ahead of schedule. Also, the fear of student isolation that many had expressed regarding technology did not accrue with these students. Rather, students collaborated more and remained interested in the technology, even with continued use. Dwyer (1994) reported a summary of the many lessons learned through the Apple Classrooms of Tomorrow project. First, technology impacts learning by encouraging different forms of interactions. The classroom moves from being teacher-centered to being learner-centered, and the student moves from being a listener to being a collaborator. Also, technology engages students to higher-order cognitive tasks. This is accomplished through problem solving activities and real-world projects. Finally, technology causes teachers to question assumptions of traditional instruction and learning.

Driscoll (2002) suggests four means by which technology can facilitate learning. First, learning occurs in context, and computer stimulations easily can provide real world types of situations to promote learning. Second, learning is active, and visualization software can substantially enhance this active learning. Third, learning is social. Technology use often requires interaction with others to achieve a prescribed goal. 
Finally, learning is reflective. As a result, technology can increase learning by promoting feedback and communication in and outside of the classroom.

Multiple studies have demonstrated potential benefits of technology for students and teachers. For example, Rodrigues (2003) completed a study in which ICT was implemented in three modes. For all three methods of integration, students reported increased motivation and interest. They enjoyed working with the multimedia aspects of ICT and found it interesting. The Apple Classrooms of Tomorrow also reported a positive impact on student engagement with the use of technology (White et al., 2002). This was especially true when technology was used as one of the many tools in the classroom. Technology possesses multiple potential benefits including enlivening class, stimulating learning, and providing student feedback (Furr et al., 2005).

Teachers often use technology because they realize the benefits for the learner (Demetriadis et al., 2003). However, teachers themselves also may benefit from technology use. It allows the enhancement of instruction, the simplification of administrative tasks, and the promotion of professional growth. Technology use also can result in enhanced classroom performance, and it often increases personal productivity (Teachers and Technology, 1995). The CEO Forum on Education and Technology (2001) also reported that technology alters the process of teaching and learning. In many cases, it improves teacher presentations and practices, and it increases teacher and student satisfaction. 


\section{Limitations and Barriers of Educational Technology}

Although educational technology holds numerous benefits, it also possesses limitations. White et al. (2002) reported that a lack of technical support is the major barrier with technology use. Wood et al. (2005) researched teachers’ perceived barriers to effective technology classroom use through surveys and focus group discussions. This was performed by random selection of 144 teachers from a mid-sized Canadian city. They found that the presence or absence of support was the issue most discussed by secondary level teachers. The needed support included materials, Internet, software, and training. It also included human resources such as technology technicians and librarians. The second most prominent issue discussed by teachers involved pedagogy. The teachers surveyed desired instruction on effectively integrating technology into their teaching methods. The third issue discussed by secondary teachers was student variables such as their motivation, skills, and characteristics. Wood et al. (2005) reported that the observation of another teacher who is knowledgeable and excited about technology can become a catalyst for other teachers to begin incorporating technology into their own classrooms. In sum, training key teachers in technology use would be one avenue of reducing the barriers of use.

Similar to the technological limitations reported by Wood et al. (2005), Iding et al. (2002) reported from their survey that many teachers were unaware of software's availability, and others were concerned with the time required to manage it properly. They indicated that technology, such as creating websites or PowerPoint, involves a substantial amount of time by most teachers. However, many teachers report that the initial time is worth the investment since technology use becomes easier with time 
(DenBeste, 2003). Wellington (1999a) indicated similar responses from chemistry teachers who were questioned about barriers in implementing multimedia technology. These included lack of technical support, lack of facilities, technical problems, lack of teacher confidence, and time. In short, teacher training is the main limitation to technology, and this can be overcome with apt professional development and teacher collaboration.

Types of Information and Communications Technology

One emerging aspect of ICT in classrooms is multimedia presentations. According to Mayer (1997), multimedia presentations involve multiple modes of communication, such as visual and auditory. This may include using computers to integrate text, graphics, video, animation, or sound (Shelly et al., 2004). These multimedia applications can be in the form of presentation aids, such as PowerPoint, or interactive learning systems (Butler \& Mautz, 1996). Multimedia use in the form of presentation software is still growing. The National Center for Education Statistics (2005) reported that $35 \%$ of teachers use presentation software.

A natural question arises of whether the use of multimedia applications in the classroom has value. Mayer (1997) demonstrated that students who received explanations in words with pictures created significantly more creative solutions when presented with a problem. Mayer believes that the coordinated explanation with pictures guides the cognitive learning process.

Multimedia presentations also can add value to teaching in specific subject areas, such as science (Wellington, 1999a, 1999b). One element it particularly can accomplish is visualization. Many science concepts are difficult to understand, and visuals may 
improve the understanding of the abstract concepts embedded in particular constructs. In Wellington's studies, multimedia instruction engaged students and generated enthusiasm. There was a reported sentiment among students that multimedia aids improved their learning of concepts.

Nevertheless, it also is important that teachers use multimedia presentations in conjunction with other effective pedagogical methods. Smith and Woody (2000) found that multimedia integration into classrooms benefited students who were visually oriented more than those who were verbally oriented. This finding was supported by Butler and Mautz (1996) whose research concluded that multimedia presentations improved the recall for individuals who preferred visually to represent information over those who preferred to verbally represent information.

An early type of multimedia instruction included interactive videodiscs (IVD). These are discs placed into a videodisc player and are viewed by students on a television screen. The teacher can navigate through various choices that may involve graphics, animations, or video clips. Lehman and Brickner (1996) studied the effects of these IVDs in science classrooms. They studied 36 teachers from the elementary to secondary levels. Overall, the teachers expressed positive attitudes towards the use of IVDs and found them to be helpful in whole-group instruction. Benefits noted by teachers included student exposure to technology, ease of use, increased student attention, and increased learning and retention.

A more recent mode of multimedia presentation used in classrooms is PowerPoint. This presentation software is used to organize and present information in a variety of formats (Heide \& Henderson, 2001). Teachers can create electronic 
presentations as an alternative to the traditional overhead or chalkboard visual displays (Shelly et al., 2004). The software contains an array of slide layouts that can be selected or created, and then the user can prepare slides of visuals and text to be viewed by the entire class. Graphics, charts, text, sound, and clip art easily can be incorporated into the presentation. Multiple studies have demonstrated that PowerPoint can benefit student engagement and interest in class with apt instructional use (Apperson et al., 2004; Frey \& Birnbaum, 2002; Koeber, 2005; Nowaczyk, Santos, \& Patton, 1998; Susskind, 2005; Szabo \& Hastings, 2000).

\section{Student Perceptions of Technology}

Assessing students' perceptions of technology is vital in recognizing its role in the educational process, and many studies have been completed on this matter. For example, Turman (2005) explored the impact of students' initial perceptions of a college course and its instructor according to the degree that instructional technology was employed. In this study, instructional technology was manipulated in four conditions: no use, minimal use, moderate use, and complete use. The classes with moderate technology integration received the most positive evaluation by the students. This finding illustrates that, although technology is valued, students still desire face-to-face connections with their classroom teachers.

Similarly, Zhang and Deng (2004) researched college students’ perceptions of learning in a multimedia classroom compared to a traditional classroom. How the students perceived their learning and the instructors' teaching methods were analyzed by surveys. No difference in the perceptions of achievement was found. However, the researchers did report a significant difference in the students' perceptions of the 
instructor's teaching methods. Students observed the multimedia classrooms to be more student-centered and interactive. The students also communicated that although technology enhanced a class, it still was the instructor who made the substantial difference in their perceptions of overall effectiveness. Butler and Mautz (1996) performed a similar study in researching the effects of multimedia presentations compared to traditional presentations in a more controlled setting. They reported that the multimedia group held more positive attitudes toward the presentation and speaker. Those in the multimedia group also perceived that they were learning more than did the non-media group.

The use of specific presentation multimedia tools, such as PowerPoint, has resulted in multiple studies assessing students’ perceptions and benefits. All of the reported studies have been completed at the college level. Koeber (2005) assessed students' perceptions of teaching with the use of PowerPoint and a class website. No significant change was observed with student grades, but an effect was observed on the effectiveness and attitudes toward the course with the technology. Students indicated that the PowerPoint presentations resulted in the teacher appearing organized and prepared. Its use also was viewed as increasing teacher control and assisting student understanding. Koeber concluded that even though technology did not affect grades, it still impacted learning because it improved other important aspects of the learning process.

Apperson et al. (2004) also assessed the impact of PowerPoint on students. In their study, students reported that PowerPoint increased their ability to focus and increased their likelihood of learning from class presentations. Although the students indicated that PowerPoint use affected their learning, grades were not significantly 
different between those who were taught with PowerPoint and those who were taught without it. Similar to Koeber’s (2005) study, PowerPoint seemed to result in a better class experience rather than student grade point average gains.

Susskind (2005) compared students' perceptions of PowerPoint compared with traditional lecture instruction. He found that students reported a clear preference for PowerPoint presentations because the lectures appeared more organized and were perceived as more interesting and enjoyable. Although students viewed themselves as more effective in the class with PowerPoint, significant achievement gains were not observed relative to student grades. Students' motivation subsequently decreased when the professor moved from using PowerPoint to traditional instruction. PowerPoint's limitations also were measured. Students reported a decrease in classroom spontaneity because the lessons seemed more pre-planned than traditional lectures. Nowaczyk et al. (1998) found that questions and discussions may not occur as often when PowerPoint is used, when compared to the traditional lecture format. Analogous to other studies, Susskind (2005) concluded that the beneficial effects of PowerPoint are relatively subjective, rather than objective (e.g., increase in students’ grades).

Frey and Birnbaum (2002) also reported on students’ positive perceptions with the use of PowerPoint. Similar to other studies, students perceived professors who used PowerPoint as more organized. Students believed that PowerPoints helped hold their attention. One trade-off students perceived with PowerPoint's use was that it may quicken the class' pace. Overall, Frey and Birnbaum concluded that PowerPoint was a valuable educational tool. 
Szabo and Hastings (2000) reported similar effects with PowerPoint's use.

Students found PowerPoint lectures more interesting and better structured than lectures with out PowerPoint. Again, students perceived that PowerPoint was beneficial to learning, but achievement gains were not established. Szabo and Hastings concluded that PowerPoint often is viewed by students as entertainment rather than as an education tool. They asserted that it should be used a supplementary medium to improve learning and not as a replacement for the blackboard.

More specifically, effects on integrating technology into the science classroom have been researched as well. Donaldson (2001) studied students' perspectives in integrated biology classrooms across grade levels. Overall, it was found that student interest in biology increased with technology use. Pedretti et al. (1998) analyzed the perspectives of teachers and students in technology-enhanced science classrooms. Students in these milieu were aware of the different teaching methods utilized compared to their traditional classes. The value students placed on technology often depended on their previous experiences and personal preferences. For instance, if the students had computers at home, they were more likely to prefer them in the classroom. Generally, students held positive views of technology; only $8 \%$ voiced strong negative views. Most students preferred learning in a technology-enhanced science classroom because it was stimulating. However, students still saw the value of hands-on lab activities and would not choose to replace these classroom engagements with technology. This sentiment was echoed by students in research by Spicer and Stratford (2001). They studied college science students' perceptions of a virtual field trip in replacing a real field trip. In this 
case, the students found the virtual field trip to be an effective learning method, but they contended that it could not replace the value of an actual field trip.

Interactive Whiteboard

The forms of ICT have evolved and revolutionized since the introduction of computers to teaching classrooms. A salient, emerging aspect of ICT is the interactive whiteboard (IWB). This holds the potential to become the new classroom chalkboard (Butler, 2005). The whiteboard appears as a large, flat screen television screen and comes in various sizes. It connects to a computer or laptop and a LCD projector. The projector displays the computer image onto the board, and the board functions as a touch screen computer monitor. Instructors can touch the board to select menus or move objects around on the board with the touch of a finger. At the bottom ledge of the board are four colored, electronic pens and an eraser to be used for writing on the board. When a pen is picked up, the pen or the teacher's finger can be used to write on the board in the selected color.

One prominent distributor of IWBs is SMART Technologies. The company was founded in 1987 and introduced the first Smart Board in 1991. In 1992, SMART joined with Intel for joint product and marketing development. Some early users of SMART Boards were educators who needed to present lectures at a distance. Its use slowly evolved in businesses and general classrooms. Today the use of the IWB is steadily rising in classrooms as SMART continues to develop new products and upgraded software (SMART Technologies, 2006).

The IWB provides a variety of classroom uses, ranging from writing notes to data manipulation. Teachers and students can use specific software to prepare and organize 
presentations with multimedia capabilities (Loschert, 2004). The SMART software allows teachers to capture and modify images or animations from files, the web, or existing software graphics. Areas of particular importance then can be emphasized by overwriting with the pens. As a science example, concepts such as mitosis can be difficult for students to grasp, but an IWB allows teachers to project animations that enhance students' conceptions about how mitosis occurs. IWBs also promote kinesthetic learning as students can interact with the board by writing and moving objects with the touch of a finger (Butler, 2005). All these IWB applications enliven concept development for students (Glover, Miller, Averis, \& Door, 2005). The IWB's uses are vast, allowing for potential seamless integration of technology into the classroom (Ziolkowski, 2004).

Research has shown IWBs to possess concrete learning benefits. Its multimedia capabilities are the main reported educational advantage. That is, an IWB allows multimedia components to be integrated easily into teacher presentations. This adds power to teaching by motivating and engaging students (Glover et al., 2005). Gerard, Green, and Widener (1999) outlined the IWB’s use in a foreign language class and established that the IWB supports teaching and learning. One way this is accomplished is by supporting interaction and conversation with students. It supports presentations by allowing teachers to overwrite on the board to highlight certain elements. This also tends to produce improved teacher organization. The IWB can promote student learning as well. For instance, Gerard et al. (1999) contends that the IWB supports the cognitive educational process because overwriting allows teachers to emphasize key concepts. This causes students to focus on essential elements and facilitates student organization of 
information. Also, Gerard et al. argue that IWBs may motivate students by generating excitement in the classroom.

In addition to these general benefits, Branzburg (2006) asserts that the IWB benefits special need students, such as those who are visually impaired because it projects large, bright visuals. Also, the IWB allows for kinesthetic learning, which is often beneficial for special need students. Wall et al. (2005) reported that non-special education students can perceive that the IWB helps special need students. The IWB's benefits for hard-of-hearing or deaf students also have been noted (Mackall, 2004). An IWB allows teachers to use technology and remain at the front of the classroom where students can see them and understand sign language.

When evaluating the IWB's use, students’ perceptions must be considered. Hall and Higgins (2005) interviewed year six students in British classrooms, assessing their reactions to the IWB's integration into the classroom. In focus groups, students identified both positive and negative contributions of the IWB. First, students noted its versatility. They commented that a range of resources could be used with the IWB. Students described the plain board as being “boring.” Second, students enjoyed the IWB's multimedia capabilities. The sounds, visuals, movements, and color increased their engagement. Third, students commented about the games that could be played with the IWB. Students also expressed factors or elements that they did not like about the IWBs. The most frequently cited feedback related to technical difficulties. For instance, if the board is bumped, it must be reoriented, and this takes time. Also, some students complained that they could not always view the board due to its size or the sun's glare. 
When asked what improvements could be made in the board's use, students said they desired more access to it. Specifically, they wanted to be able to personally use the IWB.

Wall et al. (2005) analyzed how IWBs affected students’ perceptions of their learning. This was conducted with year six British students. Overall, students provided positive sentiments and common themes were found among these constructs. First, students believed that the IWB facilitated learning. Students noted the use of visual displays, various software, and games. They believed that these items increased their concentration toward the subject matter being taught. Second, students perceived that the IWB initiated learning. The main factor they described as influencing this was motivation. Students wanted to use the board themselves. Students perceived the board as fun and preferred the visual approach to learning that the IWB afforded. Third, students commented on the IWB's multimedia capabilities. They enjoyed the integration of sounds, visuals, and colors. Subject-specific advantages were related also. Students commented on the IWB's advantages most frequently relating to math. Some stated that the IWB changed their opinion of math. Its use in science was positively reported as well as students noted its ability to aid in visualizing concepts. Students believed that the board benefited teachers by improving their concept explanations and creativity.

Although most student perceptions were positive, some negative comments were stated regarding the IWB's use in the classroom. Most of these revolved around the technical reliability of the board. Frustrations included waiting for the technology to work and reorienting the board. Lack of student participation also was noted by students. They did not feel that everyone had enough opportunity to use the board during class. Some 
students questioned whether the expense justified the IWB's benefits. Finally, some students remarked that the IWB quickened the teacher's instructional pace.

Recent developments in multimedia technology have shown benefits of its use in teaching classrooms (Butler \& Mautz, 1996; Turman, 2005; Zhang \& Deng, 2004). A specific subset of multimedia technology includes the use of PowerPoint as a presentation aid. Studies regarding PowerPoint are significant because it is one of the ways that the IWB has shown effective use. Using PowerPoint in the classroom can significantly alter the classroom environment, and this finding has generated multiple studies on students’ perceptions of its use (Apperson et al., 2004; Frey \& Birnbaum, 2002; Koeber, 2005; Susskind, 2005; Szabo \& Hastings, 2000). However, these studies all have been conducted at the college level. Research on students’ perceptions of PowerPoint at the secondary level was not acquired via an exhaustive search of the published research literature.

Summary

With the rising use of IWBs in the secondary education classroom, it is crucial to assess its value. The multiple uses of the IWB have been detailed by numerous educators (Landis, 2005; Loschert, 2004; Ziolkowski, 2004). However, modest research has been conducted on its effects. In British classrooms, Hall and Higgins (2005) and Wall et al. (2005) researched students' perceptions of the IWB focusing on the perceived benefits and limitations of its use. Since these two studies were conducted at the primary level and in European contexts, the question of how students perceive the IWB's use at the secondary level and in America remains. The view of secondary level and primary level students may differ. Thorough studies of American secondary level students' perceptions 
have not been conducted, to date. Therefore, it is necessary to explore secondary students' perceptions of the IWB's benefits and limitations.

In addition to researching the general effects of technology on education, it is also imperative to research effects in specific subject areas. Research has been performed on students' perceptions of technology in the science classroom (Donaldson, 2001; Lehman \& Brickner, 1996; Pedretti et al., 1998; Spicer \& Stratford, 2001; Wellington, 1999a, 1999b). However, the IWB has not been specifically considered in the research conducted. Subjects that have been studied with the IWB include foreign language, math, and English (Bell, 2000; Gerard et al., 1999; Zirkle, 2003). Since these studies lack in the area of secondary level students' perceptions of the IWB and in the area of science, this calls for the present necessary research. Science encompasses many facets including physics, chemistry, earth science, and biology. Their distinctive contents result in each requiring its own unique pedagogical methods. Therefore, this study concentrated on IWBs in the context of the biological aspects of teaching science. 


\section{Chapter 3}

Methodology

For this study, action research was performed using a qualitative protocol within the context of a quasi-experimental design. The goal was to assess students' perceptions of an Interactive White Board (IWB) in classroom use. In order to achieve this goal, I taught two classes on an $\mathrm{ABAB}$ and $\mathrm{BABA}$ design. During the first phase, A, I taught in the traditional manner. Then during the second phase, B, I used the IWB in my teaching. Phase A was used as a baseline so that the students could effectively compare the IWB's use with traditional instruction. The alternating design permitted a comparison of students' reflections for a certain lesson with and without the IWB. The design allowed each class to serve as its own control as well. The entire study lasted eight weeks, with each phase lasting two weeks. The following pattern was established:

Class A: 2 weeks IWB/ 2 weeks no IWB/ 2 weeks IWB / 2 weeks no IWB

Class B: 2 weeks no IWB / 2 weeks IWB/ 2 weeks no IWB/ 2 weeks IWB

Dates of Phases:

August 23-Sep 813 days

Sept 11-Sept 2210 days

Sept 25-Oct 610 days

Oct 9-Oct $25 \quad 10$ days 
The classes met daily for 90 minutes. The lessons covered during the first eight weeks of biology II included nature of science, organic compounds, cells/mitosis, and genetics. Each class contained the same content, methods, and assessments. The IWB was used to enhance visuals with the use of PowerPoint, animations, and Internet sites. In class sessions without the IWB, I used overheads and board drawings to supplement as visuals. This is the traditional method that I have used in the past.

During these eight weeks, students wrote in their journals three times per week to describe that day's class experiences with respect to technology. At the end of the eight weeks, all students were interviewed and asked about their perceived benefits and limitations of the IWB. I also asked for areas where they saw needs for improvement in the IWB's use.

Rationale for the Method

Educators commonly complete action research because it focuses on problemsolving and discovering new knowledge to inform pedagogy decisions (Johnson \& Christensen, 2004). The educational issue on which I focused was the IWB's value in the classroom. This was gauged by assessing students' perceptions, and the results are able to inform biology teachers' future uses of the IWB.

As previously noted, a paucity of research has been conducted on students' perceptions of IWBs, especially at the secondary level. Therefore, I proposed to ask a "how" question. That is, I wished to know how students came to think of their IWB experiences. In doing so, I sought to delve deeply, and I explored how students perceived the IWB's use in my biology class. This goal was best met through qualitative research in which thematic analysis was applied via transcript examination. 


\section{Population of the Study}

The population of the study consisted of sophomore, junior, and senior biology students. Particularly, the results have some degree of external validity for rural, secondary public high school students. The results of the study are most applicable to Caucasian students in the Midwest and of average socioeconomic status.

Sample

Sample criteria. The participants used in this research were the students assigned by normal scheduling to my biology II class. I collected data on all students in my classes. Class A contained 14 students and class B contained 22 students. Biology II is an upper-level biology class. The prerequisite for biology II is a minimum grade of C in biology I.

Rationale for sample. I used my assigned biology II classes because that is the most realistic population for this study. As a teacher, it is impractical to achieve a random assignment of students due to the nature of the high school setting. Since I only studied two classes, I collected data on all of my students to attain a reasonable $n$ of 14-22 students for each class. The total number of students achieved enough data collection to provide saturation and adequate external validity for the study's intended purposes.

Methods of sampling. Sampling from the population occurred through class assignment. This was determined by student selection and assignment of classes by the guidance office. No sampling occurred in the data collection process since data was collected from all students. Obviously, my classrooms constituted a sample from all rural, public, Midwest high school biology students. 


\section{Procedure}

Instruments. The instruments used for data collection involved student journals and interviews. The student journal prompts were given to students and were the same each day. For each prompt, students were asked to write a minimum of two sentences daily. Following were the prompts:

1. How was technology used in today's class activities?

Benefits:

2. If the IWB was used today, how was it helpful to you? Explain.

If the IWB was not used, what types of visuals were used, and how were they helpful?

Limitations:

3. In regards to technology, what did you not like or was not helpful about today's class?

Improvement:

4. How could have technology been better utilized in today's class?

Interview questions were prepared beforehand around the major constructs of benefits, limitations, and improvements (Appendix A).

Pilot study. The pilot study occurred four weeks into the study; this was after the first AB cycle. At this time I conducted semi-structured interviews with five students from each class to field test the interview questions. These students were randomly 
selected for the interviews. The information from the resulting interviews allowed me to revise the interview questions. This also allowed me to gauge the amount of time needed in order to accomplish my goal of 10-15 minute interviews.

Data collection methods. Two main types of data collection occurred: journals and interviews. First, students wrote in a journal three times a week. These journals were color-coded by class and remained in the classroom. I distributed the journals at the end of class for students to comment on that day's class in regards to technology. The journal prompts were typed and located in the front of each student's journal. Students dated the entry and responded to all prompts each time they wrote in the journal.

The second set of data consisted of semi-structured interviews that I conducted with each student at the end of the eight weeks (Appendix A). I attempted to complete all of the interviews within two weeks of the end of the study. Each interview lasted 10-15 minutes. After the first round of interviews was completed, I selected certain students from each class for a second round of interviews. This was based on the nature and quality of data provided, as well as emerging themes from the original transcripts. This second round of interviews occurred within three weeks of the ABAB teaching design.

Relevant ethical considerations. This action research posed no harm to the students involved. I taught in a normal manner. The only change included adding the IWB as a treatment to measure students' perceptions of its benefits and limitations. Since the students involved were minors, I obtained active informed consent from students' parents (Appendix B). They granted permission for their student to participate in the interview and have it taped and transcribed. Then I received assent from the students to agree to participate as well. Parents and students were informed that confidentiality 
would be kept throughout the process. I was the only person who knew their identity. All names used in the write-up for reading clarity are pseudonyms.

Treatment variable. The treatment variable was the use of the IWB. This was manipulated within the two classes. The assessed variables were the students' perceived benefits and limitations of the IWB. Areas that students saw need for improvements also were noted.

Methods of data analysis. All of the journal entries written by the students were organized by date. This allowed me easily to compare reactions of IWB use and traditional teaching for each entry. Each interview was transcribed and organized according to question.

Data analysis involved coding, which involved assigning category names to segments of data. The first round of coding occurred by comparing reoccurring constructs throughout the data. In doing this, I added emerging codes and removed other codes that did not frequently appear. This resulted in a master list of codes. Then I assessed the data for those codes and included themes that surfaced from the data.

Safeguards to internal and external validity. Since I conducted this study in my classroom, I engaged in self-reflection throughout the process. Also, in the results I included a discussion of how my background may have affected the research. Another means by which I contested researcher bias was by purposively looking for examples in the data that disconfirmed my expectations. This is known as negative-case sampling.

The students assigned to my biology classes represented a range of abilities and attitudes toward school. This could affect their perceptions of the IWB. To maintain validity, the ABAB design allowed each group to be used as its own control. This 
provided the students with a proper comparison of their class experience with the IWB and their class experience without it.

Also, to increase the validity of my findings I used low-inference descriptors in the analysis of the data. This means that I used words that closely matched the student's voice. I also included many direct quotes from the students to clearly communicate their perceptions.

In regards to data collection, I built internal validity through methods and data triangulation. In methods triangulation I used more than one method of data collection; I used both journals and interviews. For data triangulation, I utilized more than one data source. This occurred when I conducted multiple interviews in two waves. Another step taken was participants’ checks of their interview transcriptions. This further ensured accurate data collection.

In addition to the interview checks, I shared my tentative conclusions with a focus group. I then reflected on their feedback and how they perceived my claimed results. Obviously, my results should make sense to the participants, and their feedback should be congruent with my conclusions. Doing this further ensured internal validity.

The results of this study are not generalizable to a large population because random sampling did not occur. This negatively affects the external validity of the research. However, generalization was not the main goal. The greater purpose was to provide information to inform IWB's use in the classroom. Even though the results cannot completely be generalized to a larger target population, the results can, to some degree, be generalized to similar groups of students with teachers who possess similar characteristics to the individuals in the present project. 


\section{Chapter 4}

\section{Qualitative Analysis}

This study analyzed students’ perceptions of the IWB's use in a biology classroom. For student comparison, the overhead was used as a pedagogical control. During the phases in which the IWB was employed, I constructed PowerPoints for many of the notes; these included multiple pictures, diagrams, animations, and Internet links. Also, review activities were played that included matching games and Jeopardy. Another useful feature involved overwriting on the notes or pictures displayed with the colored electronic pens. When using the overhead, the same notes and activities were employed. However, the notes were written on transparencies with colored pens, and pictures were drawn or copied onto the transparencies. Similar review games were played also. As much as possible, the classes remained similar except for the use of technology. In fact, each student was asked in the interview to compare the way the teacher taught the material when using the IWB compared to the overhead. Most students replied that it did not change or replied that only the method, such as the use of PowerPoint, altered.

Analyzing the students' perceptions of the IWB’s use, compared to the overhead, resulted in clear educational benefits for the IWB's use. I found that the IWB increased the interest level in the classroom and improved overall instruction. Students described the IWB as interesting because it engaged them and offered multimedia aspects. Instruction also was perceived as improved by offering more appealing visuals and notes. Students articulated areas of caution in the IWB's use as well. Limitations such as computer problems, realignment issues, and writing difficulties were noted. Also, areas 
for improvement in the IWB's use were detailed by the students. These included increasing the student interaction with the IWB and including more visuals and animations in the lessons.

\section{Description of the Data}

To measure students' continued perceptions of the IWB in biology class, they wrote in their journals three times per week for the entire eight weeks of the study. This included responding to four journal prompts each day regarding the technology used. At the completion of the study, I conducted semi-structured interviews with each student. The questions were organized around the three constructs of benefits, limitations, and improvements. Each interview lasted 10-15 minutes and was tape recorded and transcribed for later analysis. Through constant comparison of the transcribed data, common themes emerged. The themes were organized into broad categories with corresponding sub-points. A focus group was then formed to share these findings and garner feedback. Further questions regarding the findings also were asked of the focus group members. A second wave of individual interviews also was conducted on select students to clarify and expand upon their previous responses. Interesting Aspects of the IWB

Engaging. Students clearly expressed the engaging aspects of the IWB as one of its main benefits. These reasons included increasing attention span, being a fun and new piece of technology, and offering variety in classroom instruction. In interview discussions with the students, many commented that the IWB was not boring when compared to the overhead. For example, Ashley stated: "I remember at the beginning of the year, I wanted to fall sleep because the overhead is boring. I've used it my entire life. 
The IWB is more interesting.” This sentiment was echoed by another student, John, who stated that the IWB “just wakes me up.” Tim also stated that “it's not boring. It's colorful, and it keeps your attention.” Since the IWB was not considered boring, it was noted to draw the students' attentions and produce a desire to learn. For instance, Sarah stated: "With the IWB you want to listen. You want to be focused. You pay attention to what you're writing down.” This idea was confirmed by multiple students such as Jacob who stated that the IWB "makes me pay more attention," and Summer who stated: "I just like it because it makes you want to learn.”

The assortment of activities offered by the IWB was one of the main reasons to which students attributed their increased attention span. This was illustrated by Carissa: "I think it does increase my attention span because it...gives more variety as you can get on the Internet and play games.” This variety was seen to increase students' interest and, thus, their overall attention levels.

Students also found the IWB engaging because it was fun. This was summed in Eric's comment when discussing the IWB: “It's fun, it’s interesting, and it helps.” The reasons given for this conclusion included that the IWB was different, more exciting, and entertaining. This was illustrated by Audrea's comment that the IWB was fun to use because it was unlike other educational tools used in class. Many students stated that it was fun due to the variety of activities offered, such as the interactive elements. For example, Jolynn stated: "When we get to interact with it it’s fun because you actually get to go up and do something and try something new.”

The fact that the IWB was a new piece of technology when compared to the overhead also engaged the students. Many students stated that they had always used the 
overhead in school. Therefore, being able to utilize a new piece of technology increased their interest in this particular class. This was clearly illustrated by Susan who stated: Since we go to Logan Elm, we don't have the best of major supplies like that and technology. I think that when we first got it, it was a really big change, and we were really happy that we were able to use something like that. We've never been able to use something like that in any of the other classes I've been in. I really like it.

When Susan was further questioned on this comment, she added that "having the best technology makes us want to learn.” Kate supported that the IWB was an interesting, new piece of technology when she stated that the "class pays more attention when you use it. It’s something new and they want to see exactly what happens.” Many students agreed with Kate and Susan in that the newness of the IWB engaged them. Brent further illustrated this point as he stated: "My attention span widens when the IWB is being used. Since it is something new to me, I want to know more about it, so I pay more attention to it.” Clearly, when questioned about the IWB, many referred to its novelty as adding an interesting aspect to the classroom.

In addition to increasing attention spans and being fun and new, the IWB also was found to offer greater variety in class activities than did the overhead. David stated: "You don't do the same thing on it everyday like you do with the overhead.” He added: "With the IWB you can do anything on it to help your students understand and to make it more interesting.” The nature of the IWB clearly allowed a greater variety in class instruction. For instance, when using the IWB, I often constructed PowerPoints, which replaced writing notes on the transparencies for the overhead. The PowerPoints contained multiple 
visuals and animations for explanation of concepts. This variety was best summed by Sam: "I like the IWB better than the overhead because there's more things you can do. You have more options. You can get animations, have notes...and you can draw on it.” The ability of the IWB to possess these sundry of uses was echoed by several students. For instance, Brian stated that the "overhead is all visual, there's nothing else. With the whiteboard there's everything rolled in one like you can get videos and sound and everything and touch.” Other students also commented that the IWB could do more than the overhead. Dave stated that “you can do interactive stuff on the Internet that you can’t do on the overhead. And you can write and it shows up on there the same as the overhead.” Many students mentioned the aspect of accessing the Internet and displaying it on the IWB. In fact, Dana stated that she liked the IWB better because "if you have a question about something you can get on the Internet and look up the answer.” In sum, the increased engagement level of students can be attributed to the IWB's ability to increase attention spans and to its being a fun and new piece of technology, offering a variety of activities for classroom instruction.

Multimedia. Students also found the IWB interesting as a result of its multimedia aspects. These included animations and the interactive elements of the IWB. The IWB allowed animations easily to be viewed by all students. These animations were retrieved from educational CD-ROMS or websites. Animations were found and shown for many common biology concepts such as cell division, osmosis, photosynthesis, DNA replication, and protein synthesis. Biology contains many detailed processes, and the animations used in class seemed to increase student understanding. 
This was illustrated in Jason's statement:

I think with the animations, they help me a lot because I can actually see what is happening. Where on the overhead...you write down the steps, and I have to picture that. With the IWB I can just see it.

Overall, the students liked the animations because they broke complex concepts into simple steps. This was expressed by Kim who stated: "It's easier to learn...with the IWB. Especially with the animations because you see exactly what the steps are and how they move. Rather with the overhead it seems like you miss out on steps.” This was echoed by Jolynn who liked the animations because they "tell you all the steps in detail and show you what happens.”

Students mentioned many specific concepts in which animations clarified their concept understandings. Particularly, cell division, including mitosis and meiosis, was mentioned frequently. In a journal entry, Patricia stated that she "liked watching the animations of mitosis and meiosis today. It refreshed my memory of their differences.” More specifically, Traci stated: "When we used the IWB for meiosis it actually showed each individual step. It was in different colors, and it made it easier to remember.” Amber similarly stated that when animations were used to explain mitosis they went "through stages and actually showed you the whole process all at once.” Many students also referred to animations that were used to help describe DNA and its replication. Daniel stated that he liked the animation of DNA replication because it "showed what was happening instead of just saying it.”

The animations not only helped students in understanding the concepts, but they also were seen to aid teacher explanation. Amanda stated that animations "help because 
we can see exactly what is happening as it is going on. And you can pause it and talk about it.” Clearly, the students enjoyed learning from the animations because they simplified difficult biology concepts into understandable steps.

The interactive elements of the IWB were mentioned to raise the interest level of the students as well. Amanda illustrated this as she stated that the IWB is "more interactive, and people pay more attention when they have to go up there and do it themselves.” Many students noted that they enjoyed the kinesthetic aspect of the IWB. For instance, Laura stated: "I think it's a good hands-on way of learning things in the classroom that will help students.” During certain lessons, students had the opportunity use the IWB in front of the class. Abby mentioned this as being beneficial, stating that she liked the IWB because "you can have lessons where someone can answer a question at the board and also do a game of matching with the board.” This particular student-use of the IWB resulted in positive comments as students seemed to enjoy their personal involvements. For instance, Amy stated: "I think the class enjoys using it because it gets them involved.”

Participants also commented that the use of the IWB not only benefited the respective student using the IWB, but it also benefited the students observing its use. For instance, Carrie stated: "I got something out of it when others were using it because it's nice to see someone my own age learning with it. And it makes me more eager to learn.” In support of this notion, Joseph stated: "I liked using it because you could see what was happening, and I think everyone was involved, even when one person was up there moving the things." 
Overall, students desired to use the IWB because it varied class activity. In regards to the interactive aspects of the IWB, many students noted the games that were played. For example, some students commented on the matching games. During these activities, students could go to the board and move items into proper categories. One activity involved matching organic compounds to the proper category of carbohydrates, lipids, proteins, or nucleic acids. Journal entries noted that students enjoyed this activity, and it seemingly increased their understanding of the different organic chemical groups. Jacob, for example, stated: "When we were doing the chemistry groups we could match up everything. I liked that.” Similarly, Jason mentioned that the "IWB was helpful because it was used to sort types of molecules...making it easier to understand.” Other students commented on review games that were played, such as Jeopardy. Students enjoyed the games because they believed it increased their involvement level more than the games played with the overhead. This is illustrated in Dave's comment regarding the IWB: "We could play games on it which is helpful because we get to be more involved in the class.”

\section{Improved Instruction}

Improved visuals. The IWB proved to be a useful tool in improving classroom instruction when compared to the overhead by enhancing both visuals and notes. Visuals were described as more colorful and more detailed on the IWB. As a result, these high quality visuals were perceived by students to improve learning. When students were asked about the visuals on the IWB, all preferred them to overhead pictures. The color, brightness, and clarity of the IWB's visuals were positive attributes often mentioned by the students. This was stated clearly by Audrea: “There’s more color on the whiteboard, 
and it's more interesting. The transparencies are just black and white. I think looking at color is more interesting than looking at black and white.” Laura referred to the IWB's sharpness and its appeal to the eye when she stated that the IWB is "a lot brighter than the overhead. That makes you want to look at it and know what you're talking about.” The colors seemed to make the pictures easier to see for the students and attract their attention more than the transparencies and colored pens used on the overhead. Many referred to the pens on the overhead as dull. On the other hand, Kim stated: "The different colors [on the IWB] help because when you draw a picture you can see it better.” Linda agreed when she stated that "it attracts my eye more because it's colorful." The various colors used on the IWB also were seen to highlight essential concepts. For instance, Tim stated that "if something is important you can put it in red and it stands out.” John also commented on the use of the colored markers on the IWB to emphasize concepts. He stated: "You can use the different markers for the writing. It gives contrast between the different parts of the subject you are teaching.” In short, students believed that the color of the IWB improved the visuals by increasing their interest and drawing their attention.

Students also perceived that the visuals contained greater detail on the IWB when compared to the overhead pictures used in lessons. This comparison was illustrated by Becky: "When you draw the pictures [on the overhead] it’s just a sketch, and you get an idea of what it looks like. When you get a picture on the IWB it's more detailed, and it makes aspects stand out more so you can see what it really looks like.” Brent supported this by simply stating that "the visuals on the IWB...are more specific and more detailed.” The visuals also were seen to be more real-to-life. For instance, John commented that the "visuals are more realistic and go more in-depth and have detail." 
The students correctly perceived that the visuals displayed with the IWB were detailed because they often were shown from on-line sites which offer a plethora of detailed pictures and diagrams. This was illustrated by Traci's comment: "On the overhead, you have to draw them out, and they aren't as detailed. On the IWB you can get them off the Internet....They are more real.” Some students also positively commented on the 3-D aspects of visuals that were possible with the IWB.

Many students discussed the benefits of the IWB for visual learners. For example, Chelsea stated that the IWB "helps the visual learner because it can give pictures and really nice diagrams." Ryan agreed in that the "visuals definitely help because they go through the process and show each step.” The slides were seen to be more understandable on the IWB than the overhead. This was illustrated in Traci's statement: "I personally like the IWB more than the overhead projector because it gives us clear simple pictures that we can understand with ease.” Many students commented that the visuals helped them remember concepts, particularly at test time. Carissa stated: "The pictures and animations make it easier to remember. When I'm taking a test, I can picture it on a test easier.” More specifically, Carissa mentioned that the "colors help me relate and remember things better.” In discussing the slides, many students referred to specific biology concepts in which quality pictures, diagrams, and animations aided their understanding. For instance, Ashley stated: "It was a lot easier to understand the cell membrane with the phospholipid bilayer...than trying to picture it in your head.”

Improved notes. In addition to improving visuals, the students also perceived the IWB to improve notes given during class discussions. Students commented that the notes were easier to view with the IWB since they were perceived as being neater and larger. 
Several students compared script modalities of the IWB and the overhead. This was clearly illustrated by David: “The notes on the IWB... are typed, and on the overhead it's just your handwriting. Sometimes there’s things you can’t read on the overhead. The IWB is just clearer.” Students preferred the typed notes on the IWB because they were easier to see and read.

The notes on the IWB also were easier to view than notes on the overhead because students perceived the notes to be larger on the IWB. For instance, Sarah stated that the IWB is “easy to read... because of how big it is.” Similarly, Summer stated the IWB is "bigger and students can focus on what it says, not if they can see it.” In addition, students commented that more notes could be placed on the IWB screen at one time than could be placed on an overhead transparency. Joseph, for example, stated: "You can fit more on one slide. You don’t have to keep changing overhead sheets.” His comment on having more space on the IWB for writing notes was echoed by several students. Many mentioned that the overhead offered little writing space per transparency; this resulted in having to use many transparencies. Kate added: "You can space the notes out [on the IWB] and use bigger font. It's easier to see and read because it's not handwritten.” Clearly, the neatness and the enlarged size of the notes eased the students' viewing.

Students also positively commented on the organization of the notes with the IWB. Many noted the preparation exercised by the teacher in developing PowerPoints for class discussions. These PowerPoints were seen to be more orderly than the notes on the overhead. In a journal entry, Sam commented: "Everything was all ready to go and organized.” Also, when Laura was asked about note-taking she replied: “I do like it better when you have the IWB because you have a PowerPoint so you go through with that. I 
think it's a lot easier to follow.” In discussing the organization of the IWB, some students detailed the manner in which notes were organized. Some referred to the bulleted notes, and others referred to the headings on each slide.

In addition to being easier to see and more organized, students also perceived note taking to be more efficient when using the IWB. This was best summed by Amy: "I think the IWB is a fast efficient way to gather information and present it to an audience because all of the information is already there.” When using the overhead, students believed that the teacher having to write out notes and switch transparencies took unnecessary time. In contrast to the overhead, when notes were given on the IWB, they were usually already typed, and the teacher only had to touch the board to move to the next slide. Susan stated: “The IWB is faster than the overhead. It's simple and easy to use and you didn't have to switch papers...like you would on the overhead.” Daniel supported the belief that class went faster with the IWB because "you can touch the slide and it changes. With the overhead you need a new transparency.” Many students believed that having the notes already written out was more organized. For instance, Brent stated that note taking "goes a lot quicker because you can prearrange stuff in a slide show." Enhancing Instruction

Limitations. As with any piece of educational technology, limitations exist. To assess this, students were asked to explain any problems or distractions that they noticed regarding the IWB's classroom use. Since it involved a computer, technical problems inevitably were one of the issues noted by students. Many mentioned the computer going into hibernation mode as a distraction. The laptop used in this classroom turned off after a specified amount of inactivity. Therefore, if the class was engaged in discussion or an 
activity, the computer would move to hibernation mode and need resurfacing. However, none of the students mentioned it as a major disruption. In fact, Jacob stated that "shutting down is not really a big problem because it only takes five seconds to turn it back on.” The other computer problem mentioned involved the Internet connection. Sometimes a link would not connect correctly or the Internet was unknowingly disabled. This inconvenience was stated by Amy: "If the link doesn't work, it slows you down and is distracting."

Having to align the IWB was another limitation students discussed. For instance, Sarah stated that the IWB was "not really distracting except when it's been bumped and [is] out of line.” At the beginning of class each day, the IWB was aligned to allow the board to respond accurately when it was written upon or touched. Often, through the course of the day, the cart that held the computer and projector was bumped. This resulted in the IWB having to be realigned, which took about ten seconds to accomplish. Again, this realignment issue was mainly mentioned as a minor distraction rather than a problem with the IWB's use. For example, when asked about having to realign the IWB, Brian responded: “It’s a hassle sometimes when you're trying to learn, but it’s not a real big deal.”

Another limitation mentioned by students involved using the four colored pens to write on the IWB. A couple students noticed that when one begins writing on the board there is a slight delay for the writing to be initially displayed. For example, Amanda was one of the students who noted: "Sometimes when you circle something or write something it takes a couple seconds for it to come up....It distracts me sometimes.” Others commented that the writing was sometimes unclear, blurry, or failed to be 
displayed. This could be attributed to handwriting or the board not being properly aligned at the time of use.

In addition to computer, realignment, and writing issues, other limitations were noted by various students. Some students found difficulty in moving objects on the board when they used the IWB. For instance, Ryan stated: “One thing I did not like about the IWB was that it was hard to drag words during the matching game.” Similarly, Abby stated: "When you have to go up [and use the board], sometimes you have trouble moving things on the board.” Another distraction about which students commented involved a box that popped on the screen when the pens were used. Dana stated that nothing was distracting with the IWB “except for when you go to click on something and that box comes up. It kind of aggravates me a little, but it really doesn’t bother me because there are more important things.” Also, a couple students noted that the variety of stimuli offered by the IWB was distracting. David stated: "Sometimes we focus more on what all it can do rather than on the material. Like how I said it's fun to watch.” Laura similarly indicated that "sometimes in class people get carried away with the animations, and they want to do that over and over gain rather than pay attention to what we are really doing."

Improvements. When queried about possible improvements, the majority of students mentioned the desire for increased interaction, visuals, and animations. In regards to increased interaction, Sarah requested more "games for a certain concept to help [us] learn.” Jolynn stated that that the teacher could “find games on the Internet where the students have to go up and play the game on the IWB....That would be good.” Brian, similarly desired that I "let us interact with it more. Maybe play, the day before 
tests, review games on it.” Other suggestions for interactivity involved having students come to the board to write notes on it. One student suggested engaging in more games as a class. For example, in the muscle unit the class went to the computer lab to work through a muscle matching activity. It was suggested that this activity be completed with the entire class on the IWB. Another student, Amber, suggested that I construct questions on slides and have each person in the class answer a question at the board with the class' assistance.

Students also requested more visuals and animations. Students desired these animations because they made the concepts easier to grasp. For example, Audrea stated: “I think more animations would be easier. They make it clearer and you can actually see what's going on.” Carrie offered an additional suggestion regarding animations: "I think if the animations were funny that would help and people would pay more attention.” Regarding these visuals and animations, students also desired that they remain colorful. Chelsea stated that "color helps people learn. It would be helpful to have different color backgrounds with each lesson.”

In addition to increasing interactivity and visuals, a few other suggestions were made. One student noted that another teacher in the building used a remote to move through PowerPoint slides. This student, Matt, preferred this method because “you don’t have to walk across the room to touch the board to advance the slide.” Overall, students did not offer many new suggestions regarding the use of the IWB. They primarily suggested that I continue and expand upon existing practices. 


\section{Summary}

In sum, this study offered insight into the student perceptions of the IWB in the biology classroom. The benefits of increasing engagement level of the students, improving visuals, and improving notes clearly emerged from the compiled data. The limitations observed by students were few and were not perceived as major disruptions. Similarly, students were reluctant to offer many areas for improvements. When ideas were mentioned they involved increasing interaction in the classroom or increasing visuals and animations. 


\section{Chapter 5}

\section{Discussion and Implications}

After analyzing the results of this action research, it is clear that the IWB can be used as a valuable educational tool in many classroom settings. The numerous benefits it offers, such as engaging students, increasing interaction, improving visuals, and enhancing notes, would be coveted by most teachers. Also, the limitations seen by students in this study were relatively few and minor and can be overcome with proper support and training. The reported results lead to practical applications and also can be compared to previous studies of the IWB.

Interpretation of the Results

Drew on the technological interest of students. In the present study, students often referred to the novelty and technological aspects of the IWB. The present world of most students is technologically savvy. Outside of the educational realm, students are inundated with multiple stimulations through mediums such as television, the Internet, and video games. Because the IWB offers a variety of stimuli, it can be used to engage these students. Particularly, the IWB may increase the attention of those who easily are distracted by traditional discussions and activities. The multimedia aspects of the IWB allow notes to be interspersed with animations, sound, realistic pictures, and games. Almost all students mentioned animations in their interviews and journals. This evidences their desire for multimedia tools in the classroom, which simply aligns with their life outside of school. 
Increased enjoyment and interest level of students during class. The IWB also was observed to increase student enjoyment and interest level during class. For example, many students referred to the visuals and notes as being more pleasing to the eye, when compared to the overhead. The overhead was viewed as sometimes blurry, dark, and boring. In contrast, the IWB was referred to as mostly bright, colorful, and stimulating. This reportedly increased students' concentration levels in class. The variety offered by the IWB was mentioned frequently by students as well. Overall, students enjoyed the variety because it resulted in a more interesting class time. Also, the interactive elements increased their engagement, for many students referred to the games as increasing their attention and interest in class.

Increased understanding of biological concepts. Simple enjoyment was not the only perceived benefit, for many students noted that the visuals, animations, and interactive elements increased their understanding of biological concepts. It was mentioned that the IWB drew on three learning styles: visual, auditory, and kinesthetic. Students perceived that visual learners were better served with the IWB than the overhead. Visuals on the IWB were seen to be more colorful, detailed, and realistic. Consequently, students saw this to increase the understanding of the concepts at hand. Students also mentioned overwriting, which allowed emphasis to be drawn on the displayed visuals. In addition to static visuals, multiple students referenced the animations as increasing their understanding of biology. When not using animations, complex concepts in biology were written out in step format, and the students had to visualize a process on their own. When using animations, the students could actually see a process occur. This seemed to clarify and deepen understandings. These animations 
allowed for greater discussions and aided students in recalling information as well. The IWB also allowed for auditory elements, which were mentioned by numerous students. For example, some animations contained auditory narrations which further eased explanation.

In addition to visual and auditory elements, the IWB also increased student understanding through its kinesthetic components. Students reported involvement with the material, which helped to clarify their understandings. Many students mentioned the matching games that were played in class which were related to learning the different organic compounds. Also, students noted that personal involvement increased their engagement levels. This further served to increase understanding, as students must be engaged in the material in order to begin the learning process.

Improved teacher instruction. The IWB not only offered student benefits, but it also improved teacher instruction by enhancing the available educational resources. In this study, the students perceived the IWB to facilitate organization of lessons. This was not an innate benefit of the IWB, but it was a secondary result of teacher planning and utilization of the IWB's resources. For instance, many students mentioned the PowerPoints used by the teacher as useful in instruction. They appreciated the organized slide format and multiple pictures and Internet links interspersed among notes. The ability of the IWB to display pictures from multiple resources such as the Internet and CD-ROMS was seen by students to increase the quality of visuals. Students also noted the typed notes on the IWB, eliminating the issue of reading the teacher's handwriting. Overwriting on displayed notes and visuals also was seen to improve instruction as students mentioned that this drew emphasis to important points. 
Useful education tool with available infrastructure and support. Given the multiple educational benefits and relatively few reported limitations, the IWB, overall, seems to be a potentially beneficial addition to teaching classrooms with the proper infrastructure and support. Based on the present study, one problem noted by students was the alignment of the IWB. However, this can be minimized with enhanced set-up. Since the projector was on a movable cart, the students noted that it often was bumped. This resulted in the IWB having to be realigned. Therefore, to minimize alignment issues, the LCD project and computer should be placed on an immovable structure.

The limitations voiced by students also provide evidence of other infrastructure elements that must be considered. For instance, consistent Internet access should be ensured. In this study, students noted that the Internet connection failed occasionally as the teacher was attempting to display particular sites. In journal entries, students also noted that students or the teacher could trip on the cords that extended from the cart to the outlet on the wall. This may pose a safety issue in classrooms; therefore, the location of the IWB must be carefully considered.

Other problems stated by students can be minimized with a greater understanding of the IWB's functions. For example, some students mentioned having difficulty with the pens or moving objects. This distraction can be solved with adequate practice and instruction with the IWB's use. Some students noted minor technical difficulties, and most of these could be alleviated with proper training or technical support. 


\section{Potential Applications of the Findings}

Carefully consider the available space and the IWB's potential use. Teachers need to consider the available classroom space when deciding how to arrange the IWB. Often classrooms are crowded, and if an IWB is being added, its placement needs to be carefully assessed. Issues to consider include available outlets, Internet access, and space for the equipment and cords. This will help determine the IWB's physical placement and the type of equipment to purchase. As stated earlier, if resources exist, a mounted board and projector are ideal. This eliminates alignment issues, as were found in the present study with a portable set-up. If a portable IWB will be used, teachers need to have a student-free area to extend the cords or a method to secure them. The potential instructional uses of the IWB must be considered as well. If the teacher plans on utilizing Internet sites, dependable Internet access is essential. Having an IWB also encourages increased student involvement. Therefore, the placement of the board so that all students can access it and easily view it is important.

Invest adequate time and resources. In addition to deciding set-up issues and potential applications of the IWB, training should be implemented for teachers. The company from which the IWB is purchased often offers training and valuable online resources. This will allow the greatest educational benefit to be gained. Once trained, teachers need to practice using the IWB and allow time to create and search for quality usable materials. In the present study, much teacher time was afforded in creating PowerPoints and searching for quality visuals and animations on the Internet and CDROMS. It also is vital that onsite technical support is available for computer problems that arise. In addition, to aid and support all teachers who use the IWBs, it would be 
valuable to have at least one teacher in the building who was widely versed in the use of the IWB.

The relatively substantial price of IWBs and its accompanying elements also must be considered. If adequate resources are not available, schools should research grants or consider buying a limited number of portable IWBs so that teachers can share them. In the present study, a limited number of IWBs was obtained through a grant, and teachers in each department shared one IWB. This was not an ideal arrangement, but it proved to be a workable situation.

Increase organization and presentation of lessons. Using software with the IWB can allow for great organization and flow of class time. For example, in the present study I constructed PowerPoints for many lessons. When developing PowerPoints, simple construction principles should be followed to allow for effective presentations. First, it is essential that the slide format aligns with the material and its method of discussion. The automatic format for PowerPoint is bulleted, and this should be modified as needed. Also, it is important that the custom animation tool be used in the development of PowerPoints. This allows segments of the slide to be displayed one at a time. This is critical when discussing notes. If all of the material is displayed at once, students reported being distracted by all the information. For instance, Sue stated that "when there are a lot of words on the PowerPoint it is kind of overwhelming." Similarly, Sarah stated that if there was material on the IWB that we were not currently discussing in class, it would distract her. To keep students focused on the material at hand, teachers should have each segment or picture on a slide be displayed as it is discussed. 
Interspersing visuals, animations, and Internet links in the PowerPoint slides also allows for expanded explanations and discussions. When slides are constructed, it is important to ensure that the font is large enough to be viewed by the entire class, for ease of viewing was a benefit of the IWB mentioned by many students. For example, many students mentioned that the notes on the IWB were easier to see because they were larger. Students also were reportedly drawn to the color of the IWB, so teachers need to experiment with different color backgrounds and contrasts for attraction and ease of viewing. Using PowerPoint with the IWB is just one avenue to increase the organization of class. IWBs also usually come with their own software that can aid the organization of visuals and notes.

Increase variety in the classroom. The IWB easily can serve to increase variety in the classroom. Using the computer, the teacher can display PowerPoints, Word documents, excel spreadsheets, or graphs and tables. The teacher can then overwrite or highlight on any of these applications to draw emphasis to specific components. Another useful function of the IWB is displaying tests, worksheets, or labs on the IWB as the teacher reviews the instructions or answers. This allows the students to follow along on their own document as the teacher highlights key words or instructions on the IWB.

Another positive addition mentioned by students that the IWB brings to the classroom is the ability to access the Internet. Internet access places a plethora of resources at ones fingertips. This allows teachers to add many quality pictures, diagrams, and animations to discussions. For example, when studying anatomy tissues, teachers can find Internet sites to display microscopic pictures of the studied tissues. These quality pictures were indicated to improve student understanding and clarify explanations. 
Useful animations also can be used from the Internet to clarify biological concepts. As found in the present study, animations were seen to engage the students and aid the learning process. These animations serve significant uses in explaining complex biological concepts such as mitosis, meiosis, photosynthesis, respiration, DNA replication, and protein synthesis. The animations can be used to introduce the subject, aid in teaching, or as a review. Searching for quality animations is time consuming. It is important to find animations to fit the academic level of the class being taught. Some available animations are too complex while others may be too simple. Games, virtual field trips, and webquests also can be found on the Internet and serve to increase variety in the classroom.

Increase involvement of students in the classroom. Finally, the IWB can serve to increase student involvement in the classroom. In the present study, many students noted that they enjoyed the hands-on aspect of the IWB. Also, in the interviews, increasing student involvement was one of the main recommendations for improvements requested by students. This can be accomplished via multiple avenues. First, the IWB software can be used to construct matching games. For example, I used the Smart Board Notebook Software to create elements as their own text box that could be moved with the touch of a finger. Then students went to the board and moved elements under the proper category. Also, matching games can be found on the Internet. In anatomy, certain websites contain matching games that can be played with the entire class or by a student at the IWB. Multiple other games can be found on the Internet or educational CD-ROMS.

It also was suggested by students that they have more opportunity to personally use the board. This would continue to increase their interest and engagement. One way 
this can be accomplished is by having students answer questions at the board in front of the class. Another way to increase involvement could occur by assigning a topic to groups to research, and then have them use the IWB to teach the subject. However, for this to succeed much time may have to be allotted for training in the IWB's use or in the construction of PowerPoints.

\section{Biblical Integration}

As a Christian educator, integrating technology, such as the IWB, into the classroom also must be analyzed from a Christian perspective. Since Creation, we have been called to be stewards with what God has provided us. In Genesis 1:28 God gives three clear commands: be fruitful, fill the earth, and subdue it. Being fruitful involves procreation, filling the earth involves adding value, and subduing involves taming the creation. Then in Genesis 2:15 these commands are reiterated as He stated that Adam and Eve were to “cultivate and keep [the garden].” Cultivate can be translated culture, and keep can be translated to take care of. Therefore, this command can be interpreted that Adam and Eve were to create culture and take care of it. Adam and Eve were to be stewards of that which was entrusted to them, and being a steward involves adding value as exemplified in the parable of the talents in Matthew.

In education, adding value includes using the available tools to further enhance the educational process. As a Christian educator, my vision of Christ needs to spill over into the manner in which I teach and structure learning activities (Young, 1991). Both the culture and educational process have embraced technology, and I must wisely use this technology in instructing my students. 
The challenge is for schools to control the introduction and use of technology to satisfy the goals of the school (Bucknall, 1991). This has been done in many Christian settings. For instance, Sherrill reported on the successful technology integration at North Raleigh Christian Academy (2003/2004). In this particular school, technology became an integral part of the school. At the start, the teachers were anxious and excited about the possibilities. In the first year of integration the teachers noted few significant educational changes. However, with more experience and training, the technology became increasingly successfully integrated. As a result of this undertaking, Sherrill, the superintendent of the school, provided advice on proper technology integration. For example, he stated that technology needs to be viewed as a tool that helps teachers teach and students learn. The best use of technology does not draw from the curriculum but, rather, supports it. Also, to be successful he emphasized that teachers need to continually update their skills through technology training. Wilcox (2005/2006) agreed in that teachers need to be committed to learning about and using technology.

Clearly, Christian educators can take the Biblical principle of stewardship and apply it to education. Technology is rapidly increasing throughout society, and this must be reflected in the classroom appropriately. I believe that with proper training and consideration, Christian educators can successfully use technology to further engage students in the learning process.

\section{Relation of the Results to Literature}

Analyzing the results in light of the current literature illumined student observations of the IWB. Previous research studies support the present finding that the IWB increases the engagement-level of students. In the current study, students generally 
referred to the overhead as dull and referred to the IWB as new and exciting. Similarly, students in Hall and Higgins' (2005) study with the IWB, which occurred in British primary classrooms, viewed the plain board as boring and believed that the multimedia aspects of the IWB engaged and held their interests. In fact, a student in Hall and Higgins' study made the comment that the plain board caused them to fall sleep. This same comment was made by students in the present research. Students in Wall et al.'s (2005) study, which similarly occurred in British primary classrooms, also perceived the IWB to aid concentration and increase motivation. Similarly, Beeland's (2002) study reported that students observed lessons with the IWB as more interesting, and this resulted in increasing students' attention. Wellington's (1999a) study of multimedia instruction in chemistry classes found comparable results. He reported that multimedia elements increased the enjoyment of students and grabbed and maintained their attention. In the present study, PowerPoint was used often as a multimedia element in the classroom. Reported results of other studies have confirmed that PowerPoint has the ability to increase interest and attention (Frey \& Birnbaum, 2002; Susskind, 2005; Szabo \& Hastings, 2000).

The IWB also has proven to offer a variety of resources, as observed by students. Similar to this study, students in Hall and Higgins' (2005) research appreciated the range of resources provided by the IWB. Their students mentioned the Internet, educational software, and games. Students in the present research also referenced these applications as cogent. Wall et al.’s (2005) study also revealed that students appreciated the variety offered by the classroom technology and believed that the IWB facilitated learning through the different software applications. The variety of the IWB includes its 
interactivity, which I found students to view positively. Hall and Higgins' (2005) and Beeland's (2002) studies both reported positive comments by students in regards to the IWB's interactivity. Beeland stated that the interactive elements helped the students learn and resulted in a more fun and interesting class time. The fun attribute also was noted by students in the current study.

The finding that the IWB increased student understanding also is supported by previous research. In the present study, the improved visuals and animations were viewed as key elements for increasing understanding. Research by Wall et al. (2005) also reported the IWB's visuals to promote learning. Students positively mentioned science and noted the elements of "realism" that the IWB allowed. Many students in the current study also viewed the visuals as being colorful, in-depth, detailed, and realistic. Wellington's (1999a) study on multimedia instruction reported similar results regarding the added value of technology. He found that technology offered attractive graphics and dynamic images and animations. In addition, Gabric et al.’s (2005) findings were congruent with the present research which indicated that quality visuals and animations improved student understanding of biological concepts. In contrast to other studies, the perceived value of animations was a prominent issue discussed by students in the present research. Previous research minimally mentioned the student perception of animations. For instance, Hall and Higgins (2005) noted that students in their studies enjoyed the visual aspects that included color and movement. Also, Wellington (1999a) mentioned that technology aided understanding as a result of the movement of visuals.

Overall, the use of the IWB did not substantially affect student grades when compared to previous classes or between studied classes. Rather, the main results of 
using the IWB seemed to be an increased student interest in class time. This is similar to other research which reported that the use of PowerPoint mainly affected student appeal, not student achievement (Susskind, 2003; Szabo \& Hastings, 2000). For example, Szabo \& Hastings found that students reported PowerPoint as being beneficial to learning; however, grades did not reflect an increase in learning.

The IWB not only affected student enjoyment and learning, but it was found also to affect teacher instruction. Students in the current study perceived the IWB to improve teacher explanation and organization. Similarly, Wall et al. (2005) found that the IWB helped teachers explain concepts and caused them to be more enthusiastic and innovative. Gerard et al. (1999) also reported that the IWB promoted teacher organization skills and improved presentations through the overwriting tool. Students in the current research also perceived the overwriting tool to aid instruction. I found that students mainly observed lessons to be more organized as result of my use of PowerPoint. Many studies have shown PowerPoint to increase the organization of a class, as observed by students (Frey \& Birnbaum, 2002; Susskind, 2005; Szabo \& Hastings, 2000).

The reported limitations of the IWB's use in the present study also can be compared to previous research. The main disadvantages of the IWB, as discussed by Hall and Higgins (2005), included technical difficulties and alignment issues. My students also viewed both of these as distractions. However, students in Hall and Higgins' study also reported that viewing the board was an issue. Many mentioned the sun's glare on the IWB and that the IWB was not centered in the classroom. This was not noted by many of my students. The IWB used in the present study was fairly large and was placed in the center of the classroom. Also, the blinds were closed on sunny days to eliminate a glare. 
Wall et al. (2005) also discovered similar results with respect to the limitations of the IWB. Students in their study reported negatively on the technical reliability of the board, and they did not like having to wait for the IWB to start up and shut down. Similarly, students in my classroom also mentioned some technical problems that included the computer shutting off after inactivity and then having to restart it.

Students in the current study also mentioned problems with their personal use of the board. These included experiencing trouble writing on the board and moving objects. Hall and Higgins (2005) reported similar difficulties by students. As a result, Hall and Higgins maintained that students need to practice using the IWB to improve their skills.

The areas noted in the present research for improvement proved to be similar to those reported by previous studies as well. Students in Hall and Higgins’ (2005) study asked to personally use the IWB more. This request was made by students in the current study also. However, the students in Hall and Higgins' study also indicated the student use of the IWB as being inequitable, and they attributed that to unfair teacher selection of students. In contrast, none of the students in the present study mentioned that student use of the IWB was inequitable. When opportunities for student use arose in my classroom, I usually asked for volunteers. Those who desired to use it received a chance. However, some students preferred to observe its use. As a result, students had multiple opportunities to use the IWB, if they desired. These differing student perceptions between Hall and Higgins' research and the current study may be a result of teacher selection methods or attitudes of primary level students versus high school level students. Therefore, the issue of student use of the IWB may be more of a teacher issue or philosophy than an innate issue with the IWB. In the present study, students also 
requested additional visuals and animations. This desire by students was not discussed in other studies.

Strengths of the Study

This project involved action research which resulted in seemingly robust findings that can be applied to other educational settings. The ABAB design of the study allowed each class to serve as its own control. Since each class received a total of four weeks of both overhead and IWB instruction, on an alternating schedule, students were able to clearly differentiate each instrument's instructional effects. Most students had little exposure to the IWB before this study; therefore, their previous experience and bias were minimal factors in analyzing the results.

Unlike many previous studies, this research focused on the IWB's use in one classroom and, thus, focused on its effects on biology instruction. The IWB was the only differing variable in the two classes. As much as possible, other variables such as instructor, activities, assessments, and labs were kept constant between the two groups. Therefore, this allowed students to draw relatively focused conclusions on their differing perceptions of class time with the use of the overhead and IWB. Also, addressing one subject area allowed greater detail and depth of discussion, especially in regards to the IWB increasing student understanding of concepts. The reported results, thus, are most applicable to the biology classroom setting.

The methods of data collection involved triangulation and saturation of data. Having the students write in journals three times a weeks allowed their daily views to be analyzed. These then were compared to their final views as voiced in the interviews at the study's completion. All students were interviewed which provided a rich data set. The 
interviews were transcribed, and then participant checks of the transcripts were completed to ensure accuracy. After the results were analyzed and common themes were found, I discussed the findings with a focus group of four students and with five students during their second interview. The data from these interviews further confirmed the findings. Analysis of the transcripts and journal entries showed consistent and repeated results. Saturation was apparent as additional data collection likely would not have produced novel results.

\section{Limitations of the Study}

Remaining threats to internal validity. Using student interviews and journals resulted in a wide range in the depth and detail of information offered by students. Many students disseminated a wealth of data in interviews and journals, but a few students provided relatively little in comparison. Interviews with the latter proved to be shorter as these students sometimes failed to expound upon their replies to questions when prompted. However, given that I interviewed all students, enough data was collected to provide apt findings that represented the groups' consensus.

Another limitation encountered was the lack of random selection in the second wave of interviews. Students who participated in the focus group or a second interview could not be randomly selected due to difficulties in scheduling times for interviews. Rather, I asked for student volunteers, and I granted each volunteer a small amount of extra credit for participation. This may have resulted in more motivated students participating in the second wave of interviews.

Since this procedure was conducted only in two classes, it resulted in a relatively small data set. As a result of scheduling constraints, the classes were also uneven in 
number. One class contained 14 students while the other class contained 22 students. However, I built a guard into the study’s design to lesson this potential threat to internal validity. Particularly, the ABAB design resulted in each class serving as its own control where students received instruction via both modalities.

From the observed results, the IWB was new to most of the students in the study, and it was also new to me, as the teacher. Since the study was conducted during the first eight weeks of school, this was the first exposure of the IWB for many students. As a result, the study captured the students' fascination of this new piece of technology. However, the novelty of the IWB may subside later in the school year. The possibility of this effect could not be studied given the time confines of the present research.

Another limitation involved my limited prior use of the IWB. I had used the IWB for one month prior to the beginning of the study, having received one brief training session. Since it was an exciting new educational tool, I was ambitious in its use and strived to utilize the technology to its best potential. However, I may not have fully understood all of its functions and applications. This may have resulted in some of the limitations students voiced.

Remaining threats to external validity. As a result of high school scheduling, random selection could not occur in class formation. Therefore, most of the students involved in the study consisted of higher level students who were ambitious to take an advanced biology class. The diversity of the students also was limited. All the students were Caucasian and lived in rural settings. As a result, this study was highly focused on a select group of students, and, therefore, the results are not wholly generalizable to all grades in the United States. That is, one cannot take the present findings and generalize 
them across multiple high school populations. However, beneficial educational information still can be gleamed from the study and applied in many classrooms sharing similar demographic characteristics.

Suggestions for Future Research

For future research, this study should be expanded to include a greater number of schools with diverse groups of students. Also, how students perceive the IWB needs to be analyzed in different types of science classes such as chemistry, physics, and earth science to draw comparisons among the sciences.

Since this study focused on qualitative issues and drew the conclusion that the IWB had an overall positive effect on students' experiences, the next logical step would be to analyze these effects quantitatively. For example, students in this study perceived that the IWB improved learning. Now, actual academic effects that the IWB has on learning should be assessed. This would further the qualitative findings reported in the present research, promoting theory development and formal hypothesis testing.

Another area for future research involves analyzing the perspectives of teachers who regularly use the IWB in their classroom. This would further inform areas of effective pedagogical methods and practical suggestions for limiting problems and seen distractions. As more classroom teachers adopt this technology in their respective classrooms, such research likely will become feasible- particularly for comparison among teachers with multiple-levels of experiences. 


\section{APPENDIX A \\ INTERVIEW QUESTIONS}

1. Compare the IWB to the overhead. What do you like about each and why?

2. What do you dislike about each (IWB and overhead) and why?

\section{Benefits}

3. Everyone learns differently. Some like visuals, auditory, or movement. In what ways do you think the IWB helps you learn, compared to the overhead? Give specific examples.

4. Compare your interest/engagement level in class when using the IWB versus the overhead. Does it change? If so, explain how?

5. Why do you think it changes in this manner (as mentioned above)?

6. Can you think of a specific instance when the IWB changed your engagement level? Explain how the IWB was used and why it changed your engagement.

7. Compare the way the teacher teaches the material when using the IWB compared to the overhead. Does it change? If so, explain.

8. Compare how notes are given in class when using the IWB compared to the overhead.

9. Would you prefer the overhead or the IWB for notes and why?

10. Many visuals and diagrams are often shown in class. Compare the quality of these with the IWB versus the overhead. Be specific in the differences.

11. Think about the concepts we learned in biology so far this year (nature of science, chemistry, cells, photosynthesis, cells, genetics...). Explain two concepts in which the IWB helped in your understanding. How did the IWB help? 


\section{Limitations}

12. What do you not like about the IWB? Is anything distracting? Explain.

13. What problems have you noticed with the IWB? Give specific examples of any problems that have happened in class.

14. Have you been able to use the IWB? If so, how easy or difficult is the IWB to use? Explain.

Improvements

15. Explain two things that your teacher could do with the IWB to make lessons more interesting.

16. Do you have any other teachers who use the IWB? If so....

Compare how I use it to how your other teacher uses the IWB.

17. What makes a teacher "good” at using the IWB? Explain.

18. Please give a final summary statement on the comparison of the IWB and the overhead. 


\section{APPENDIX B \\ PARENTAL CONSENT FORM}

August 23, 2006

\section{Dear Parent/Guardian,}

I hope that you had a wonderful summer and your student is ready for an exciting semester in Biology II. This summer I was working towards my Masters in Education at Cedarville University. This has been a beneficial experience, and I will be using many of the methods and ideas gained in class.

As I near the completion of my masters, I will be working on my thesis this year; this is my final project. I will be researching students' perceptions of the Smart Board. This is an awesome new piece of technology that the school received with funds from a grant. Since it is a recent addition in the classroom, it is important to measure its effectiveness and the value students place on it in my biology class. The results of this research will inform future instruction and use of the Smart Board.

To achieve this goal, I will be alternating use of the Smart Board with the overhead projector for the first eight weeks of school. Both of these are effective teaching methods. During this time, your student will keep a journal on the use of the Smart Board and his/her perceptions. At the end of the eight weeks, I will conduct a 20 minute interview with each student. This will occur from October 25- November 1. Most of these will be conducted before or after school. Some interviews will be able to be completed if your student's lunch or study hall coincides with my prep. Your student will receive extra credit for participating in the interview. There is also the possibility of a focus group being formed to garner students' collective ideas regarding the Smart Board.

At this time I am requesting your permission for your student to have his/her interview taped and transcribed. All information from the interview will be kept confidential and names will be changed in any reports. Please sign and return the permission slip below by August 28. I appreciate your cooperation. Feel free to email me if any questions arise.

Sincerely,

Miss Schut 
I give permission for my student to participate in an interview regarding his/her perceptions of the Smart Board. I also grant permission for the interview to be taped and transcribed. I understand that confidentiality will be maintained.

Student's name:

Date:

Parent's signature: 


\section{REFERENCES}

Albirini, A. (2006). Teachers' attitudes toward information and communication technologies: The case of Syrian EFL teachers. Computers, 47, 373.

Apperson, J. M., Laws, E. L., \& Scepansky, J. A. (2004). The impact of presentation graphics on students' experience in the classroom. Computers \& Education, 47, 116-123.

Apple Computers. (1995). Teaching, learning, \& technology: A report on 10 years of ACOT research. Retrieved September 1, 2006 from http://www.apple.com/education/k12/leadership/acot/library.html

Beeland, W. D. (2002). Student engagement, visual learning, and technology: Can interactive whiteboards help? Retrieved July 31, 2006, from http://www.smarttech.com

Bell, M. A. (2000). Impact of electronic whiteboard on student attitudes and achievement in eighth-grade writing instruction. Unpublished doctoral dissertation, Baylor University.

Branzburg, J. (2006). Use an interactive whiteboard: Get a handle on how this technology can spice up the classroom. Technology \& Learning, 26(6), 31.

Brown, D. (2006). From the university to the elementary classroom: Students’ experiences in learning to integrate technology in instruction. Journal of Technology and Teacher Education, 14, 599-621.

Bucknall, R. (1991). Information technology in schools. Journal of Christian Education, 102, 7-13. 
Butler, J. B., \& Mautz, D. (1996). Multimedia presentations and learning: A laboratory experiment. Issues in Accounting Education, 11, 259-280.

Butler, L. L. (2005). Chalk, what chalk? Journal of Physical Education Recreation and Dance, 75, 12-13.

The CEO Forum on Education and Technology (2000). School technology and readiness report. The power of digital learning: Integrating digital content. Washington, DC: Author. Retrieved July 27, 2006, from http://www.ceoforum.org/downloads/ report3.pdf

The CEO Forum on Education and Technology (2001). School technology and readiness report: Student achievement in the $21^{\text {st }}$ century assessment, alignment, accountability, access, analysis. Washington, DC: Author. Retrieved July 27, 2006, from http://www.ceoforum.org/downloads.report4pdf.

Cuban, L. (2001). Oversold and overused: Computers in the classroom. Cambridge, MA: Harvard University Press.

Culp, K. M., Honey, M., \& Mandinach, E. (2003, October). A retrospective on twenty years of education technology policy. Washington, DC: U.S. Department of Education, Office of Technology.

Demetriadis, S., Barbas, A., Molohides, A., Palaigeorgiou, G., Psillows, D., Vlahavas, I., et al. (2003). “Cultures in negotiation:” Teachers’ acceptance/resistance attitudes considering the infusion of technology into schools. Computers and Education, 41, 19-37.

DenBeste, M. (2003). Power Point, technology, and the web: More than just an overhead projector for the new century? History Teacher, 36, 491-504. 
Donaldson, A. (2001). Biology exploration through technology: Taking the leap from theory to practice. TechTrends, 45(5), 27-34.

Driscoll, M. P. (2002). How people learn (and what technology might have to do with it. Syracuse, NY: ERIC Clearinghouse on Information and Technology. (ERIC Document Reproduction Service No. ED470032)

Dwyer, D. (1994). Apple classrooms of tomorrow: What we've learned. Educational Leadership, 7(51), 4-10.

Elementary and Secondary Education Act (ESEA). (2001). No child left behind act of 2001. Retrieved July 31, 2006, from http://www.ed.gov/policy/elsec/let/esea02.index.html

Frey, B. A., \& Birnbaum, D. J. (2002). Learners' perceptions on the value of PowerPoint in lectures (Report No. IR 021417). University of Pittsburgh. (ERIC Document Reproduction Service No. ED467192)

Furr, P. F., Ragsdal, R., \& Horton, S. G. (2005). Technology’s non-neutrality: Past lessons can help guide today's classroom. Education and Information Technologies, 10, 277-287.

Gabric, K. M., Hovance, C. Z., Comstock, S. L., \& Harnisch, D. L. (2005). Scientists in their own classroom: The use of type II technology in the science classroom. Computers in the Schools, 22, 77-89.

Gerard, F., Green, M., \& Widener, J. (1999, February). Using SMART board in foreign language class. Paper presented at Society for Information Technology \& Teacher Education Conference, Antonio, TX. 
Glover, D., Miller, D., Averis, D., \& Door, V. (2005). The interactive whiteboard: A literature survey. Technology, Pedagogy, and Education, 14, 155-170.

Hall, I., \& Higgins, S. (2005). Primary school students’ perceptions of interactive whiteboards. Journal of Computer Assisted Learning, 21, 102-117.

Heide, A., \& Henderson, D. (2001). Active learning in the digital age classroom. Portsmouth, NH: Heinemann.

Henderson, H. (1999). Issues in the Information Age. San Diego, CA: Lucent Books. Iding, M., Crosby, M. E., \& Speitel, T. (2002). Teachers and technology: Beliefs and practices. International Journal of Instructional Media, 29, 153-170.

Introduction-What is ICT? (2006). Retrieved July 26, 2006, from http://www.tutor2u.net/business/ict/intro_what_is_ict.htm

Johnson, B., \& Christensen, L. (2004). Educational research: Quantitative, qualitative, and mixed approaches. Boston: Pearson.

Kirkwood, A., \& Price, L. (2005). Learners and learning in the twenty-first century: What we know about students' attitudes towards and experiences of information and communication technologies that will help us design courses? Studies in Higher Education, 30, 257-274.

Koeber, C. (2005). Introducing multimedia presentations and a course website to an introductory sociology course: How technology affects student perceptions of teaching effectiveness. Teaching Sociology, 33, 285-300.

Landis, M. (2005, March/April). Eight ways to integrate whiteboard into instruction. Media and Methods, 41, 4. 
Lawrenz, F., Gravely, A., \& Ooms, A. (2006). Perceived helpfulness and amount of use of technology in science and mathematics classes at different grade levels. Technology in Science and Mathematics Classes, 106, 133-139.

Lehman, J. D., \& Brickner, D. (1996). Teacher's uses and perceptions of interactive videodiscs in the science classroom. The Journal of Computers in Mathematics and Science, 15, 85-102.

Lockard, J., \& Abrams, P. D. (2001). Computers for twenty-first century educators. New York: Longman.

Loschert, K. (2004, September). Bye, bye, blackboard. NEA E-News. Retrieved on July 31, 2006, from http://www.teachsmart.org/teachingSmarter/Presentation_Notes.asp

Loveless, A. M. (2003). The interaction between primary teachers' perceptions of ICT and their pedagogy. Education and Information Technologies, 8, 313-326.

Mackall, P. (2004). Interactive whiteboards enhance the learning experience for deaf, hard-of-hearing students. THE Journal, 31(10), 64-66.

Mayer, R. (1997). Multimedia learning: Are we asking the right questions? Educational Psychologist, 32, 1-19.

National Education Technology Plan. (2004). Toward a new golden age in american education: How the Internet, the law, and today's students are revolutionizing expectations (Publication No. ED 000259P) .Washington, DC: U.S. Department of Education. 
National Center for Education Statistics. (2005, March). Computer technology in the public school classroom: Teacher perspectives (NCES Publication No. 2005083). Washington, DC: U.S. Department of Education.

Nowaczyk, R., Santos, L., \& Patton, C. (1998). Student perception of multimedia in the undergraduate classroom. International Journal of Instructional Media, 25, 367-382.

Pedretti, E., Mayer-Smith, J., \& Woodrow, J. (1998). Technology, text, and talk: Students' perspectives on teaching and learning in a technology-enhanced secondary science classroom. Science Education, 82, 569-589.

Pelgrum, W. J. (2001). Obstacles to the integration of ICT in education: Results from a worldwide educational assessment, Computers and Education, 38, 163178.

Roblyer, M. D. (2006). Integrating educational technology into teaching. New York: Merrill Prentice-Hall.

Rodrigues, S. (2003). Conditions pupil disposition, autonomy, and effective use of ICT in science classrooms. The Educational Forum, 67, 266-275.

Shelly, G. B, Cashman, T. J., Gunter, R. E., \& Gunter, G. A. (2004). Integrating Technology in the Classroom ( ${ }^{\text {rd }}$ ed.). Boston, MA: Course Technology. Sherrill, S. (2003/2004). Virtual tour of twenty-first-century technology. Christian School Education, 7(3), 38-40.

Simpson, G. (2005). Incorporating ICT in the secondary science classroom. Teaching Science, 51(3), 44-47. 
SMART Technologies, Company Info. (2006). Retrieved July 26, 2006, from http://www.smarttech.com/company/aboutus/index.asp.

Smith, S. M., \& Woody, P. C. (2000). Interactive effect of multimedia instruction and learning styles, Teaching of Psychology, 27, 220-223.

Spicer, J. I., \& Stratford, J. (2001). Student perceptions of a virtual field trip to replace a real field trip. Journal of Computer Assisted Learning, 17, 345-354.

Stallard, C. H., \& Cocker, J. S. (2001). The promise of technology in schools: The next 20 years. Lanham, MD: The Scarecrow Press.

Susskind, J. E. (2005). PowerPoint's power in the classroom: Enhancing students' self-efficacy and attitudes. Computers, 45, 203-215.

Sutherland, R., Armstrong, V., Barnes, S., Brawn, R., Breeze, N., \& Gall, M., et al. (2004). Transforming teaching and learning: Embedding ICT into everyday classroom practices. Journal of Computer Assisted Learning, 20, 413-425.

Szabo, A., \& Hastings, N. (2000). Using IT in the undergraduate classroom: Should we replace the blackboard with PowerPoint? Computers \& Education, 35, 175-187.

Turman, P. (2005). The influence of instructional technology on students’ affect: Do course designs and biological sex make a difference. Communication Studies, 56, $109-129$.

U.S. Congress, Office of Technology Assessment. (1995). Teachers and Technology: Making the Connection (Publication No. OTA-HER-616). Washington, DC: U.S. Government Printing Office. Vail, K. (2003). School technology grows up. American School Board Journal, 190(9), 34-37. 
Venezky, R. (2004). Technology in the classroom: Steps toward a new vision. Education, Communication \& Information, 4, 1-21.

Voogt, J., Almekinders, M., Van Den Akker, J., \& Moonen, B. (2005). An in-service arrangement for classroom technology integration: Impacts on teachers and students. Computers in Human Behavior, 21, 523-539.

Wall, K., Higgins, S., \& Smith, H. (2005). 'The visual helps me understand the complicated things’: Pupil views of teaching and learning with interactive whiteboards. British Journal of Educational Technology, 36, 851-867.

Wellington, J. (1999a). Integrating multimedia into science teaching: Barriers and benefits. School Science Review, 81, 49-54.

Wellington, J. (1999b). Multimedia in science teaching: Friend or foe? Physics Education, 34, 351-359.

Wheeler, S. (2001). Information and communication technologies and the changing role of the teacher. Journal of Education Media, 26, 11-17.

White, N., Ringstaff, C., \& Kelley, L. (2002). Getting the most from technology in schools. (Report No. IR 021860). Washington, DC: Office of Educational Research and Improvement. (ERIC Document Reproduction Service No. ED 471137)

Wilcox, E. (2005/2006). Better business. Using technology effectively. Christian School Education, 9(3), 21.

Williams, D., Coles, L., Wilson, K., Richardson, A., \& Tuson, J. (2000). Teachers and ICT: current use and future needs. British Journal of Educational Technology, 31, 307-320. 
Wiske, S. (2000). A new culture of teaching for the $21^{\text {st }}$ century. In D. Gordon (Ed.), The digital classroom (pp. 69-77). Cambridge, MD: The Harvard Education Letter.

Wood, E., Mueller, J., Willoughby, T., Specht, J., \& DeYoung, T. (2005). Teacher’s perceptions: Barriers and supports to using technology in the classroom. Communication \& Information, 5, 183-206.

Young, R. (1991). Technology and the Word: A personal note. Journal of Christian Education, 102, 23-28.

Zhang, S., \& Deng, H. (2004). Perception of learning effectiveness in the multimedia classroom vs. the traditional classroom: A case study. Media Review, 11, 87-107.

Zhao, Y., \& Cziko, G. A. (2001). Teacher adoption of technology: A perceptual control theory perspective. Journal of Technology and Teacher Education, 9, 5-30.

Ziolkowski, R. (2004, Jan/Feb). Interactive whiteboards: Impacting teaching and learning. Media \& Methods, 40(4), 44.

Zirkle, M. L. (2003) The effects of SMART board interactive whiteboard on high school students with special needs in a functional mathematics class. Retrieved July 31, 2006, from http://www.smarttech.com 
